Portland State University

PDXScholar

\title{
The Effect of a Ferrite-Core Relay Vs. an Air-Core Relay on the Output Power Characteristics of a Three-Coil Wireless Power Transfer System
}

Jakob L. White

Portland State University

Follow this and additional works at: https://pdxscholar.library.pdx.edu/honorstheses

Part of the Electrical and Electronics Commons, Electromagnetics and Photonics Commons, and the Power and Energy Commons

Let us know how access to this document benefits you.

\section{Recommended Citation}

White, Jakob L., "The Effect of a Ferrite-Core Relay Vs. an Air-Core Relay on the Output Power Characteristics of a Three-Coil Wireless Power Transfer System" (2021). University Honors Theses. Paper 1134.

https://doi.org/10.15760/honors.1165

This Thesis is brought to you for free and open access. It has been accepted for inclusion in University Honors Theses by an authorized administrator of PDXScholar. Please contact us if we can make this document more accessible: pdxscholar@pdx.edu. 
The Effect of a Ferrite-Core Relay Vs. an Air-Core Relay on the Output Power Characteristics of a Three-Coil Wireless Power Transfer System

AN UNDERGRADUATE HONORS THESIS SUBMITTED IN PARTIAL FULFILLMENT OF THE REQUIREMENTS FOR THE DEGREE OF

BACHELOR OF SCIENCE

IN

UNIVERSITY HONORS

AND

ELECTRICAL ENGINEERING

Author:

JAKOB WHITE

Thesis Advisor:

DAVID BURNETT

Date:

August 17, 2021

Maseeh College of Engineering and Computer Science

PORTLAND STATE UNIVERSITY 


\begin{abstract}
The purpose of this thesis is to determine the effect of using a ferrite-core relay on the output power characteristics of a three-coil, parallel-tuned, domino-resonator wireless power transfer (WPT) system in comparison to the effect of using an air-core relay in such a system. First, a general mathematical model is presented to describe both the ferrite-core-relay system and the air-core-relay system and to calculate their output power characteristics for seven different resistive loads at each of five different distance configurations between the coils. Next, experimental results are analyzed and compared to the mathematical results to confirm model accuracy. Finally, the output power characteristics of the two systems are compared and contrasted. The results of this thesis show that the model is most accurate when working with loads around $1 \mathrm{k} \Omega$, exhibiting an error of about $25 \%$. More importantly, maximum power output is achieved when working with loads around $1 \mathrm{k} \Omega$, at which the average improvement to output power when using a ferrite core instead of an air core is about $87 \%$. Therefore, it can be concluded that, with coil geometries and operating frequencies being held constant, the inclusion of a ferrite core in relay coils can noticeably improve output power characteristics at a given distance between coils. The reason for this improvement is most probably the result of magnetic flux concentration by the ferrite core, which in turn increases induced current and therefore output power.
\end{abstract}

\title{
Index Terms
}

Wireless Power Transfer, WPT, Three-Coil, Ferrite-Core, Long-Distance, Parallel-Tuned. 


\section{Contents}

I Introduction 4

II System Modeling and Mathematical Analysis

II-A General Model and Math . . . . . . . . . . . . . . . . . . . . . . . . . 5

II-B $\quad$ Taidacent WPT System Model and Math . . . . . . . . . . . . . . . . . . . . . 11

III Experimental Setup and Procedure 12

III-A Experimental Procedure . . . . . . . . . . . . . . . . . . . . . . . . 16

IIII-B $\quad$ Experimental Data . . . . . . . . . . . . . . . . . . . . . . . . . . . 16

\begin{tabular}{lll}
\hline IV Results & 17
\end{tabular}

\begin{tabular}{|lr}
\hline$\quad$ Discussion and Conclusion & 20 \\
\hline
\end{tabular}

V-A Comparison of Model and Experiment . . . . . . . . . . . . . . . 20

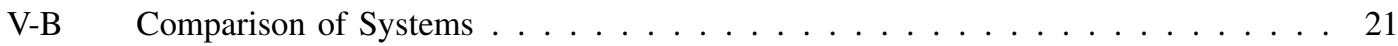

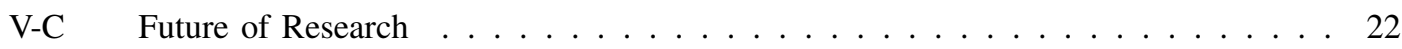

\begin{tabular}{|ll}
\hline VI Appendix: Datasheets & 23 \\
\hline
\end{tabular}

\begin{tabular}{|ll}
\hline VII Appendix: MATLAB Code & 24 \\
\hline
\end{tabular}

\begin{tabular}{lll}
\hline VIII Acknowledgment & 53
\end{tabular}

\begin{tabular}{lll}
\hline IX $\quad$ References & 54
\end{tabular}

Biographies 55

Jakob White . . . . . . . . . . . . . . . . . . . . . . . . . . . 55 


\section{List of Figures}

1 The General Structure of the WPT System in Question $\ldots \ldots \ldots \ldots \ldots$

$2 \quad$ The Circuit Model of the WPT System in Question $\ldots \ldots \ldots \ldots \ldots \ldots$

$3 \quad$ The Theoretical Transformation of the Ferrite Core. . . . . . . . . . . . . . . . . . . 9

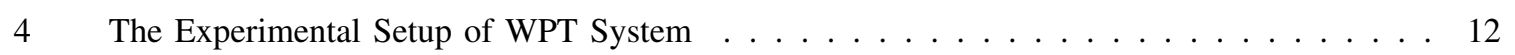

$5 \quad$ The Experimental Transmitter (TX) Setup $\ldots \ldots \ldots \ldots \ldots \ldots \ldots$

$6 \quad$ The Experimental Receiver $(\mathrm{RX})$ Setup $\ldots \ldots \ldots \ldots \ldots \ldots$

$7 \quad$ The Experimental Air-Core Relay Setup . . . . . . . . . . . . . . . . . . . . . . . . . . . . . 14

$8 \quad$ The Resonance of the Experimental Air-Core Relay Setup . . . . . . . . . . . . . . . . . . . . 14

$9 \quad$ The Experimental Ferrite-Core Relay Setup . . . . . . . . . . . . . . . . . . . 15

$10 \quad$ The Resonance of the Experimental Ferrite-Core Relay Setup . . . . . . . . . . . . . . 15

11 Output Power Characteristics of the Air-Core-Relay WPT System . . . . . . . . . . . . . 17

12 Output Power Characteristics of the Ferrite-Core-Relay WPT System . . . . . . . . . . . 18

13 The Relative Performance of Air-Core and Ferrite-Core at $1 \mathrm{k} \Omega$. . . . . . . . . . . . . . . 19

14 Datasheet for the Taidacent Transmitter . . . . . . . . . . . . . . . . 23

15 Datasheet for the Taidacent Receiver . . . . . . . . . . . . . . . . . 23

\section{List of Tables}

I Geometric Parameters, Their Definitions, and Their Datasheet Values in the Taidacent WPT

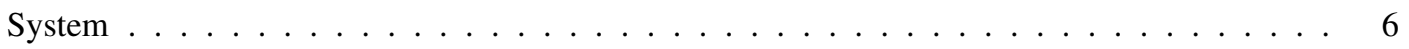

II $\quad$ Circuit Parameters, Their Definitions, and Their Datasheet Values in the Taidacent WPT System 6

III $\quad$ Air-Core Model Data in $[\mu \mathrm{W}] \ldots \ldots \ldots \ldots \ldots \ldots \ldots \ldots$

IV $\quad$ Ferrite-Core Model Data in $[\mu \mathrm{W}] \ldots \ldots \ldots \ldots \ldots \ldots \ldots \ldots \ldots \ldots$

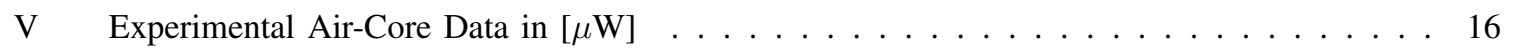

VI $\quad$ Experimental Ferrite-Core Data in $[\mu \mathrm{W}] \ldots \ldots \ldots \ldots \ldots \ldots \ldots \ldots \ldots$

VII $\quad$ Average Air-Core Model Error for Each Load . . . . . . . . . . . . . . . . . . . . . . 20

VIII $\quad$ Ferrite-Core Average Model Error for Each Load . . . . . . . . . . . . . . . . . . . . . 20

IX Average Percent Increase in Output Power When Switching from Air-Core Relay to Ferrite-

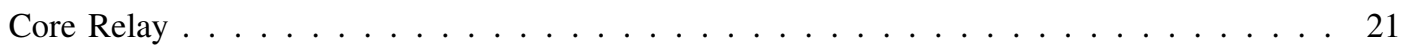




\section{Introduction}

$\mathbf{I}^{\mathbf{r}}$

$\mathrm{N}$ recent years, Wireless Power Transfer (WPT) has become increasingly important for the remote powering of many wireless devices such as wearable electronics, chemical sensors, and communication devices [1]. Generally, the overall objective of any WPT system is to deliver just enough power as efficiently as possible with the greatest degree of freedom of position and orientation between the transmitter and receiver. Still, WPT systems can be classified according to power delivery and transmission distance. A WPT system is either High Power (15W to $100 \mathrm{~W}$ ), Medium Power ( $5 \mathrm{~W}$ to $15 \mathrm{~W}$ ), or Wearable (up to $5 \mathrm{~W}$ ) [2], and either Long Range (coil-radius-to-distance ratio is much greater than 3), Medium Range (coil-radius-to-distance ratio is greater than 3), or Short Range (coil-radius-to-distance is ratio less than 3) [3]. In some wearable long-range applications, such as the wireless nodes being developed by Dr. Burnett [4], efficiency isn't nearly as important as maximum power delivery and compactness of the receiver. Several papers have been produced discussing the various options to increase the power delivery in long-range WPT systems, from metamaterials to relays. In regard to the latter, researchers have primarily experimented with series-tuned WPT systems using air-core coils and have not experimented with parallel-tuned WPT systems [5]. Furthermore, while other researchers have shown the promising results of using ferrite cores to increase WPT transmission distance and efficiency, they do not discuss using ferrite cores with the relay coil [6]. Therefore, the objective of this thesis is to determine the effect of using a ferrite-core relay on the output power characteristics of a three-coil, parallel-tuned, dominoresonator wireless power transfer (WPT) system in comparison to the effect of using an air-core relay in such a system.

In order to accomplish this objective, this thesis is divided into three parts. In the first part, a general mathematical model is derived to represent the interactions between the transmitter, relay, and receiver in a three-coil WPT system. This model is then used to derive the theoretical behavior of a Taidacent High Power Long-Distance Wireless Power Supply Module [7] using both an air-core relay and a hollowcylinder ferrite-core relay. The usage of a hollow-cylinder ferrite core instead of a standard ferrite rod is justified as a compromise between increased power transmission and weight [8]. The output power to each of seven loads between $1 \Omega$ and $1 \mathrm{Mega} \Omega$ at each of five distance configurations between the coils is measured for both the air-core-relay and ferrite-core-relay systems. For each of the distance configurations, the transmitter and receiver coils are placed at a certain distance apart, and the relay is placed at a point where the output voltage is maximum. In the second part, experiments are conducted with a real Taidacent High Power Long-Distance Wireless Power Supply Module to reflect and confirm the calculations of the mathematical model. Finally, in the third part, the mathematical model and experimental results are analyzed and compared to determine model accuracy for both the air-core-relay and ferrite-core-relay systems. These two systems are also compared to each other to determine the effect that a ferrite core has on the output power characteristics relative to a traditional air core. The implication of this research is that a new way of using ferrite cores in WPT systems will be revealed, possibly enabling more-efficient and longer-range WPT for low-power wireless devices. 


\section{System Modeling and Mathematical Analysis}

\section{II-A General Model and Math}

The general WPT system structure used in this thesis is shown in Fig. 1. The coils are all planar and concentric, and the receiver is simply a parallel-tuned RLC circuit. The only difference between the aircore-relay system and the ferrite-core-relay system is that, to compensate for the change in inductance resulting from the introduction of a ferrite core, the compensation capacitor of the relay is changed in proportion to maintain the same resonant frequency. Coil geometry remains constant. See Tables I and II for parameter definitions.

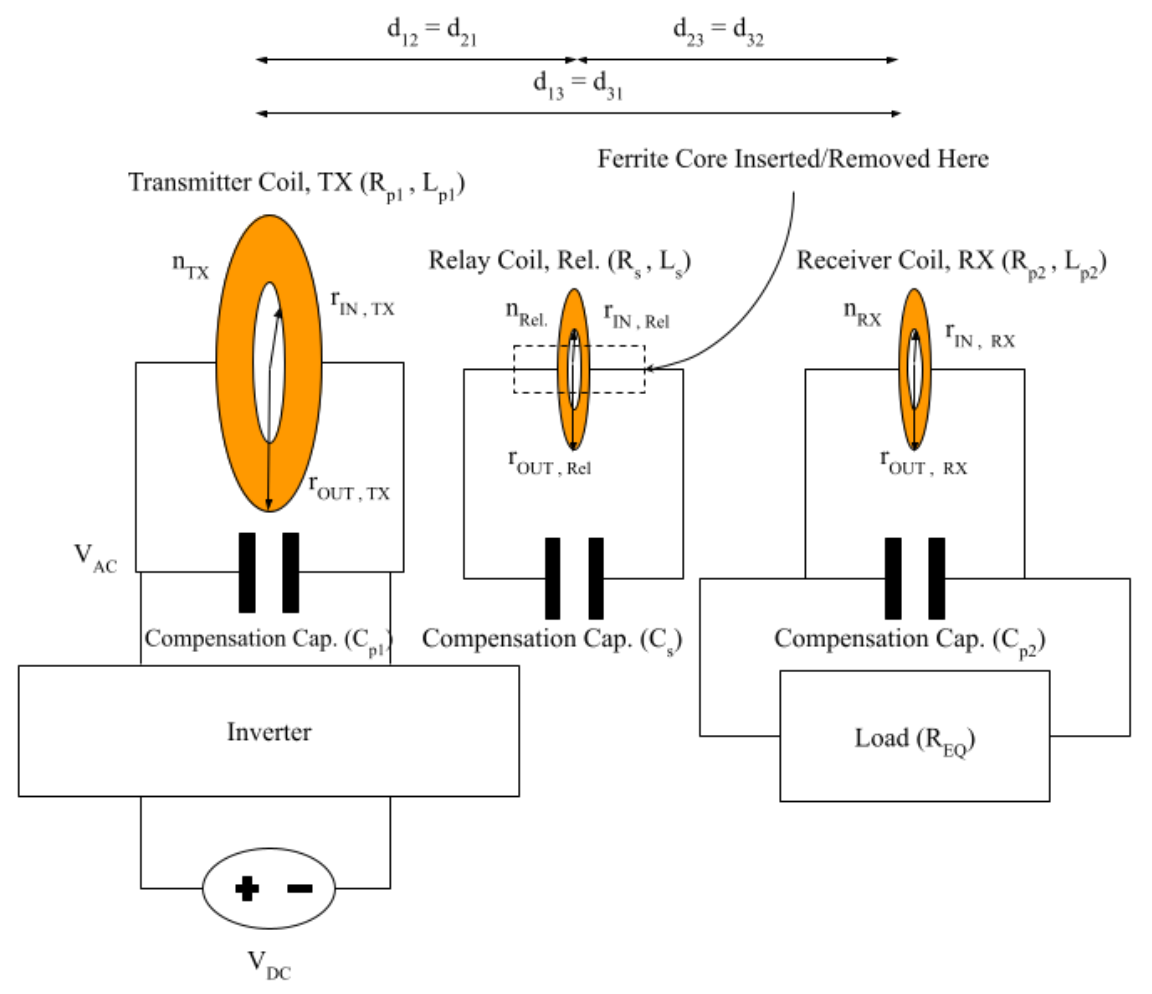

Fig. 1: The General Structure of the WPT System in Question. The "Inverter" serves to turn the DC power supply voltage into a higher AC voltage at the resonant frequency of the transmitter's LC circuit. 


\section{SYSTEM MODELING AND MATHEMATICAL ANALYSIS}

\begin{tabular}{|c|c|c|}
\hline \multicolumn{3}{|c|}{ Geometric Parameters } \\
\hline Parameter & Definition & Value \\
\hline$d_{12}, d_{21}$ & Distance between TX and Rel. Coils & $d_{13}-d_{23}$ \\
\hline$d_{13}, d_{31}$ & Distance between TX and RX Coil & {$[0.2,0.4,0.6,0.8,1.0] \mathrm{m}$} \\
\hline$d_{23}, d_{32}$ & Distance between Rel. and RX Coils & $\sim 15 \mathrm{~mm}$ to $\sim 50 \mathrm{~mm}$ \\
\hline$r_{\text {out }} T X$ & Outer Radius of TX Coil & $100 \mathrm{~mm}$ \\
\hline$r_{\text {out }}$ Rel. & Outer Radius of Rel. Coil & $25 \mathrm{~mm}$ \\
\hline$r_{\text {out }}{ }_{R X}$ & Outer Radius of RX Coil & $25 \mathrm{~mm}$ \\
\hline$r_{i n_{T X}}$ & Inner Radius of TX Coil & $95 \mathrm{~mm}$ \\
\hline$r_{i n_{R e l}}$. & Inner Radius of Rel. Coil & $15 \mathrm{~mm}$ \\
\hline$r_{i n_{R X}}$ & Inner Radius of RX Coil & $15 \mathrm{~mm}$ \\
\hline$w_{T X}$ & Width of TX Coil Wire & $1.19 \mathrm{~mm}$ \\
\hline$w_{\text {Rel }}$. & Width of Rel. Coil Wire & $0.445 \mathrm{~mm}$ \\
\hline$w_{R X}$ & Width of RX Coil Wire & $0.445 \mathrm{~mm}$ \\
\hline$s_{T X}$ & TX Coil Pitch & $0 \mathrm{~mm}$ \\
\hline$s_{\text {Rel. }}$. & Rel. Coil Pitch & $0 \mathrm{~mm}$ \\
\hline$s_{R X}$ & RX Coil Pitch & $0 \mathrm{~mm}$ \\
\hline$n_{T X}$ & Number of Turns in TX Coil & 5 \\
\hline$n_{\text {Rel. }}$. & Number of Turns in Rel. Coil & 15 \\
\hline$n_{R X}$ & Number of Turns in RX Coil & 15 \\
\hline$r_{\text {Out }}$ Core & Outer Radius of Ferrite Core & $15.1 \mathrm{~mm}$ \\
\hline$r_{\text {In }}$ & Inner Radius of Ferrite Core & $8.95 \mathrm{~mm}$ \\
\hline$l_{\text {Core }}$ & Length of Ferrite Core & $15.4 \mathrm{~mm}$ \\
\hline$r_{s}$ & Average Radius of Relay Coil & $20 \mathrm{~mm}$ \\
\hline$r_{f}$ & Radius of Equivalent Ferrite Rod & $12.2 \mathrm{~mm}$ \\
\hline
\end{tabular}

TABLE I: Geometric Parameters, Their Definitions, and Their Datasheet Values in the Taidacent WPT System

\begin{tabular}{|c|c|c|}
\hline \multicolumn{3}{|c|}{ Circuit Parameters } \\
\hline Parameter & Definition & Value \\
\hline$V_{D C}$ & Input DC Power Supply Voltage & $24 \mathrm{~V}$ \\
\hline$V_{A C}$ & Voltage Across TX LC Circuit & $\sim 100 \mathrm{~V}$ \\
\hline$R_{p 1}$ & Series Resistance of TX Coil & $\sim 0.02 \Omega$ \\
\hline$L_{p 1}$ & Self Inductance of TX Coil & $14 \mu \mathrm{H}$ \\
\hline$C_{p 1}$ & Compensation Capacitance for TX Coil & $39 \mathrm{nF}$ \\
\hline$R_{s}$ & Series Resistance of Rel. Coil & $\sim 0.02 \Omega$ \\
\hline$L_{s}$ & Self Inductance of Rel. Coil & $\sim 20 \mu \mathrm{H}$ \\
\hline$C_{s}$ & Compensation Capacitance for Rel. Coil & $27 \mathrm{nH}$ \\
\hline$R_{p 2}$ & Series Resistance of RX. Coil & $\sim 0.02 \Omega$ \\
\hline$L_{p 2}$ & Self Inductance of RX. Coil & $\sim 20 \mu \mathrm{H}$ \\
\hline$C_{p 2}$ & Compensation Capacitance for RX. Coil & $27 \mathrm{nH}$ \\
\hline$R_{E Q}$ & Resistive Load & Use Eq. 1 \\
\hline$I_{1}$ & Current in Lp1 & Use Eq. 1 \\
\hline$I_{2}$ & Current in Lp2 & Use Eq. 1 \\
\hline$I_{3}$ & Current in Lp3 & Use Eq.'s 2 and 9 \\
\hline$\omega$ & Resonant/Operation Frequency & Use Eq.'s 2 and 9 \\
\hline$M_{12}$ & Mut. Ind. between TX and Rel. & Use Eq.'s 2 and 9 \\
\hline$M_{21}$ & Mut. Ind. between Rel. and TX & Use Eq.'s 2 and 9 \\
\hline$M_{13}$ & Mut. Ind. between TX and RX & Use Eq.'s 2 and 9 \\
\hline$M_{31}$ & Mut. Ind. between RX and TX & Use Eq.'s 2 and 9 \\
\hline$M_{23}$ & Mut. Ind. between Rel. and RX & 1.38 \\
\hline$M_{32}$ & Mut. Ind. between RX and Rel. & $10001000000]$ \\
\hline$\mu_{c o r e}$ & Average Permeability of Hollow Cylinder Ferrite Core & \\
\hline
\end{tabular}

TABLE II: Circuit Parameters, Their Definitions, and Their Datasheet Values in the Taidacent WPT System 
The WPT system circuit model used in this thesis is shown in Fig. 2. Using Kirchhoff's Voltage Law, a matrix can be formed and used to solve for the currents in the inductors of the system. See Table I for parameter definitions.

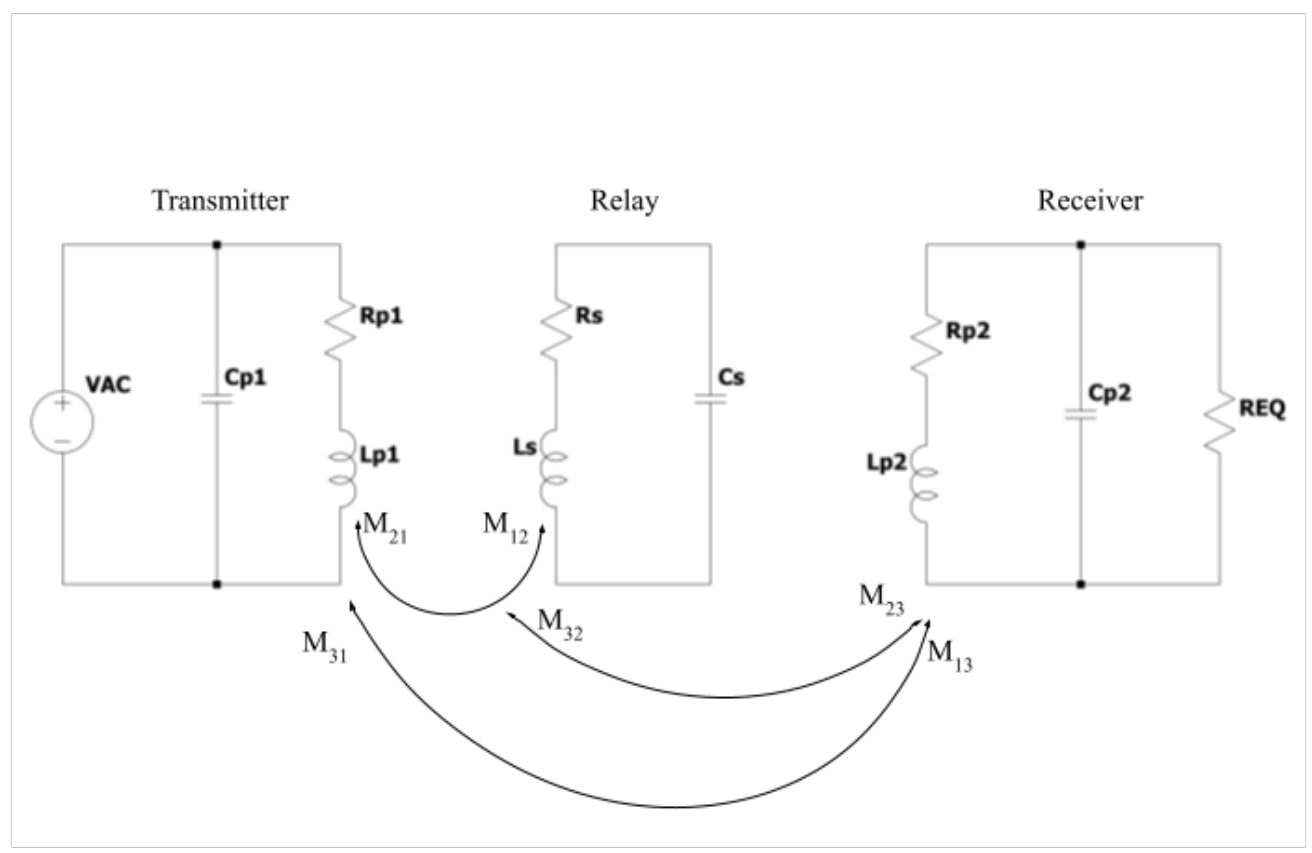

Fig. 2: The Circuit Model of the WPT System in Question. The coils are modeled with both their self-inductances and their series resistances. As for the DC voltage source and the inverter, they have been replaced with an equivalent AC voltage source. The mutual inductances or "M's" are the result of coil geometries and relative positions and orientations.

$$
\left[\begin{array}{c}
V_{1} \\
0 \\
0
\end{array}\right]=\left[\begin{array}{ccc}
R_{p 1}+j \omega L_{p 1} & j \omega M_{12} & j \omega M_{13} \\
j \omega M_{21} & R_{s}+j\left(\omega L_{s}-\frac{1}{\omega C_{s}}\right) & j \omega M_{23} \\
j \omega M_{31} & j \omega M_{32} & R_{p 2}+j \omega L_{p 2}+R E Q \| \frac{-j}{\omega C_{p 2}}
\end{array}\right]\left[\begin{array}{c}
I_{1} \\
I_{2} \\
I_{3}
\end{array}\right]
$$

Since this thesis uses a pre-manufactured WPT system with available datasheets, all of the parameters can be obtained easily except for the mutual inductances. These require analytical models dependent on coil geometries and orientations. 


\section{II-A1 Air-Core Mutual Inductance}

From [9], the mutual inductance between two circular air-core planar coils is given by equations (2) - (7).

$$
\begin{gathered}
M=\rho \times \sum_{i}^{i=n_{p}} \sum_{j}^{j=n_{s}} M_{i j} \\
M_{i j}=\frac{\mu_{0} \pi a_{i}^{2} b_{j}^{2}}{2\left(a_{i}^{2}+b_{j}^{2}+d^{2}\right)^{\frac{3}{2}}}\left(1+\frac{15}{32} \gamma_{i j}^{2}+\frac{315}{1024} \gamma_{i j}^{4}\right) \\
a_{i}=r_{\text {out }_{p}}-\left(n_{i}-1\right)\left(w_{p}+s_{p}\right)-\frac{w_{p}}{2} \\
b_{j}=r_{\text {out }_{s}}-\left(n_{j}-1\right)\left(w_{s}+s_{s}\right)-\frac{w_{s}}{2} \\
\gamma_{i j}=\frac{2 a_{i} b_{j}}{\left(a_{i}^{2}+b_{j}^{2}+d^{2}\right)} \\
\rho=1
\end{gathered}
$$

Where the parameters are as follows,

- $M$ is the Total Mutual Inductance

- $M_{i j}$ is the Mut. Ind. between Loop i of Primary and Loop $j$ of Secondary

- $r_{\text {out }}$ Outer Radius of Primary Coil

- $r_{\text {out }}$ Outer Radius of Secondary Coil

- $n_{p}$ is the Number of Turns in Primary Coil

- $n_{s}$ is the Number of Turns in Secondary Coil

- $w_{p}$ is the Width of Copper Wire in Primary Coil

- $w_{s}$ is the Width of Copper Wire in Secondary Coil

- $s_{p}$ is the Track Separation in Primary Coil

- $s_{s}$ is the Track Separation in Secondary Coil

- $\rho$ is a Constant Dependent on Coil Shape (in this case circular)

- $d$ is the Coaxial Distance between Coils

Note that, here, $M$ can represent any total mutual inductance between any pair of primary and secondary coils. For example, "primary" could mean the coil of the transmitter and "secondary" could mean the coil of the relay, or vice versa, or some other combination of different coils. 


\section{II-A2 Ferrite-Core Mutual Inductance}

Although a hollow-cylinder ferrite core is used, for analysis purposes it can be approximated as an equivalent ferrite rod with a radius smaller than that of the innermost loop of the planar coil. The reasoning behind this extends from the approach in [10] and was later confirmed by matching model data to experimental data. The transformation is done as follows,

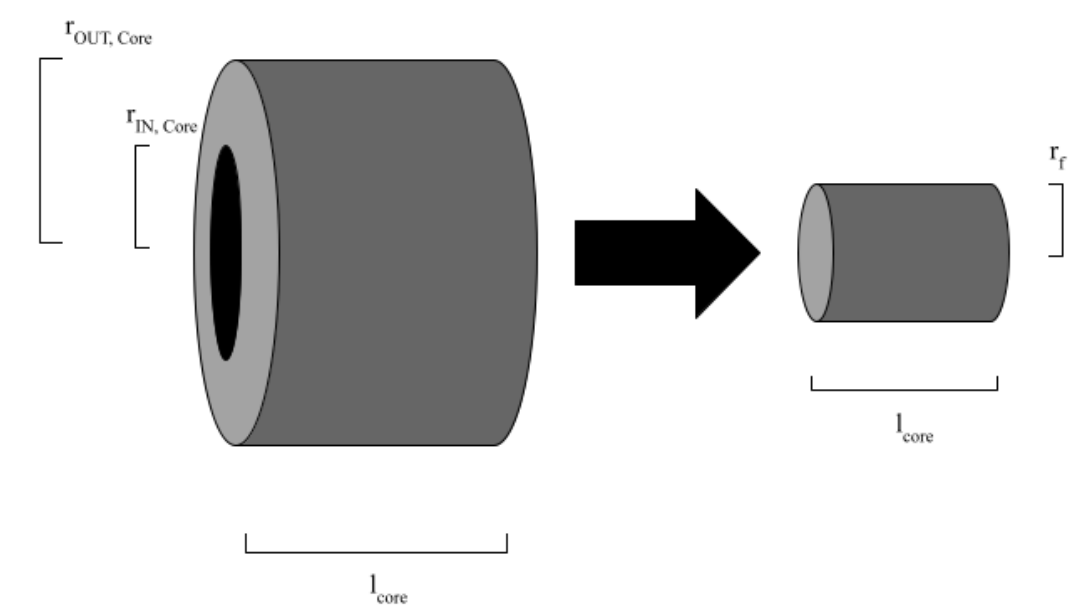

Fig. 3: The Theoretical Transformation of the Ferrite Core.

$$
r_{f}=\left(r_{O U T_{\text {Core }}}^{2}-r_{I N_{\text {Core }}}^{2}\right)^{\frac{1}{2}}
$$


From [11], when the average radius of the coil is larger than the radius of the core, the mutual inductance can be approximated as follows,

$$
\begin{gathered}
M=M_{\text {AirCore }}\left[\left[1-\frac{r_{f}^{2}}{r_{s}^{2}}\right]+\frac{\mu_{\text {Core }_{A v g}}}{1+D_{f c}\left(\mu_{\text {Core }_{A v g}}-1\right)}\left[\frac{r_{f}^{2}}{r_{s}^{2}}\right]\right] \\
D_{f c}=\frac{3.966(0.5 K)^{-0.056}}{|d|^{3}}\left(\frac{1}{K^{2}}\right)[|d|-\arctan |d|] \\
K=\frac{l_{\text {core }}}{r_{\text {core }}} \\
d=\left[1-\left(\frac{2^{2}}{K}\right)\right]^{\frac{1}{2}}
\end{gathered}
$$

Where the parameters are as follows,

- $M$ is the Total Mutual Inductance

- $M_{\text {AirCore }}$ is the Mut. Ind. in Calculated as Though Ferrite Core is Removed

- $r_{\text {In }}$ Core is the Inner Radius of Hollow Ferrite Cylinder

- $r_{\text {Out }}$ Core is the Outer Radius of Hollow Ferrite Cylinder

- $r_{f}$ is the Equivalent Radius of Ferrite Rod

- $l_{\text {core }}$ is the Length of Ferrite Core

- $r_{s}$ is the Average Radius of Coil

- $\mu_{\text {Core }}$ avg is the Average Permeability of Core

- $D_{f c}$ is the Demagnetization Factor 


\section{II-B Taidacent WPT System Model and Math}

With the general math model, the specific parameters of the system under test can be used to determined the theoretical output power characteristics. See Tables I and II for parameter values. For each of the distance configurations, the output power is calculated as the load is swept logarithmically from $1 \Omega$ to $1 \mathrm{Mega} \Omega$. See Tables III and IV for the output power characteristics. The distance configurations are as follows:

- Configuration \#1: $d_{13}=0.2 \mathrm{~m}, d_{23}$ determined experimentally by point of maximum voltage (see Tables III and IV)

- Configuration \#2: $d_{13}=0.4 \mathrm{~m}, d_{23}$ determined experimentally by point of maximum voltage (see Tables III and IV)

- Configuration \#3: $d_{13}=0.6 \mathrm{~m}, d_{23}$ determined experimentally by point of maximum voltage (see Tables III and IV)

- Configuration \#4: $d_{13}=0.8 \mathrm{~m}, d_{23}$ determined experimentally by point of maximum voltage (see Tables III and IV)

- Configuration \#5: $d_{13}=1.0 \mathrm{~m}, d_{23}$ determined experimentally by point of maximum voltage (see Tables III and IV)

\begin{tabular}{|c|c|c|c|c|c|}
\hline & Configuration \#1 & Configuration \#2 & Configuration \#3 & Configuration \#4 & Configuration \#5 \\
\hline $\mathbf{1} \Omega\left(d_{23}=0.015 \mathbf{m}\right)$ & 2660 & 51.9 & 4.36 & 0.72 & 0.174 \\
\hline $\mathbf{1 0} \Omega\left(d_{23}=0.015 \mathbf{m}\right)$ & 21100 & 411 & 34.5 & 5.72 & 1.38 \\
\hline $\mathbf{1 0 0} \Omega\left(d_{23}=0.02 \mathbf{m}\right)$ & 48800 & 917 & 76.5 & 12.6 & 3.09 \\
\hline $\mathbf{1 0 0 0} \Omega\left(d_{23}=0.045 \mathbf{m}\right)$ & 82700 & 1120 & 103 & 17.5 & 4.17 \\
\hline $\mathbf{1 0 0 0 0} \Omega\left(d_{23}=0.05 \mathbf{m}\right)$ & 17900 & 283 & 22.4 & 3.62 & 0.873 \\
\hline $\mathbf{1 0 0 0 0 0} \Omega\left(d_{23}=0.05 \mathbf{m}\right)$ & 1950 & 30.8 & 2.04 & 0.396 & 0.0957 \\
\hline $\mathbf{1 0 0 0 0 0 0} \Omega\left(d_{23}=0.05 \mathbf{m}\right)$ & 197 & 3.11 & 0.205 & 0.0400 & 0.00966 \\
\hline
\end{tabular}

TABLE III: Air-Core Model Data in $[\mu \mathrm{W}]$

\begin{tabular}{|c|c|c|c|c|c|}
\hline & Configuration \#1 & Configuration \#2 & Configuration \#3 & Configuration \#4 & Configuration \#5 \\
\hline $\mathbf{1} \Omega\left(d_{23}=0.015 \mathbf{m}\right)$ & 2710 & 52.8 & 4.44 & 0.736 & 0.178 \\
\hline $\mathbf{1 0} \Omega\left(d_{23}=0.015 \mathbf{m}\right)$ & 21900 & 428 & 36.0 & 5.97 & 1.45 \\
\hline $\mathbf{1 0 0} \Omega\left(d_{23}=0.03 \mathbf{m}\right)$ & 52900 & 996 & 83.3 & 13.85 & 3.38 \\
\hline $\mathbf{1 0 0 0} \Omega\left(d_{23}=0.05 \mathbf{m}\right)$ & 96300 & 1280 & 119 & 20.2 & 4.81 \\
\hline $\mathbf{1 0 0 0 0} \Omega\left(d_{23}=0.05 \mathbf{m}\right)$ & 21100 & 331 & 26.0 & 4.20 & 1.01 \\
\hline $\mathbf{1 0 0 0 0 0} \Omega\left(d_{23}=0.05 \mathbf{m}\right)$ & 2300 & 36.0 & 2.35 & 0.460 & 0.110 \\
\hline $\mathbf{1 0 0 0 0 0 0} \Omega\left(d_{23}=0.05 \mathbf{m}\right)$ & 232 & 3.64 & 0.236 & 0.0464 & 0.0111 \\
\hline
\end{tabular}

TABLE IV: Ferrite-Core Model Data in $[\mu \mathrm{W}]$ 


\section{Experimental Setup and Procedure}

The basis of the experimental setup is the Taidacent High Power Long-Distance Wireless Power Supply Module. However, the coils still need to be mounted so that they could be easily moved along a concentric line. Therefore, the setup shown in Fig. 4 is implemented, and the individual modules and their measured values are presented in Fig. 5 - 8. In addition, the following equipment was used for the experiments:

- Siglent 1202X-E Oscilliscope, which is used to measure the peak-to-peak voltages of the output waveforms across the load resistances.

- TackLife DC Power Supply, which is used to power the transmitter.

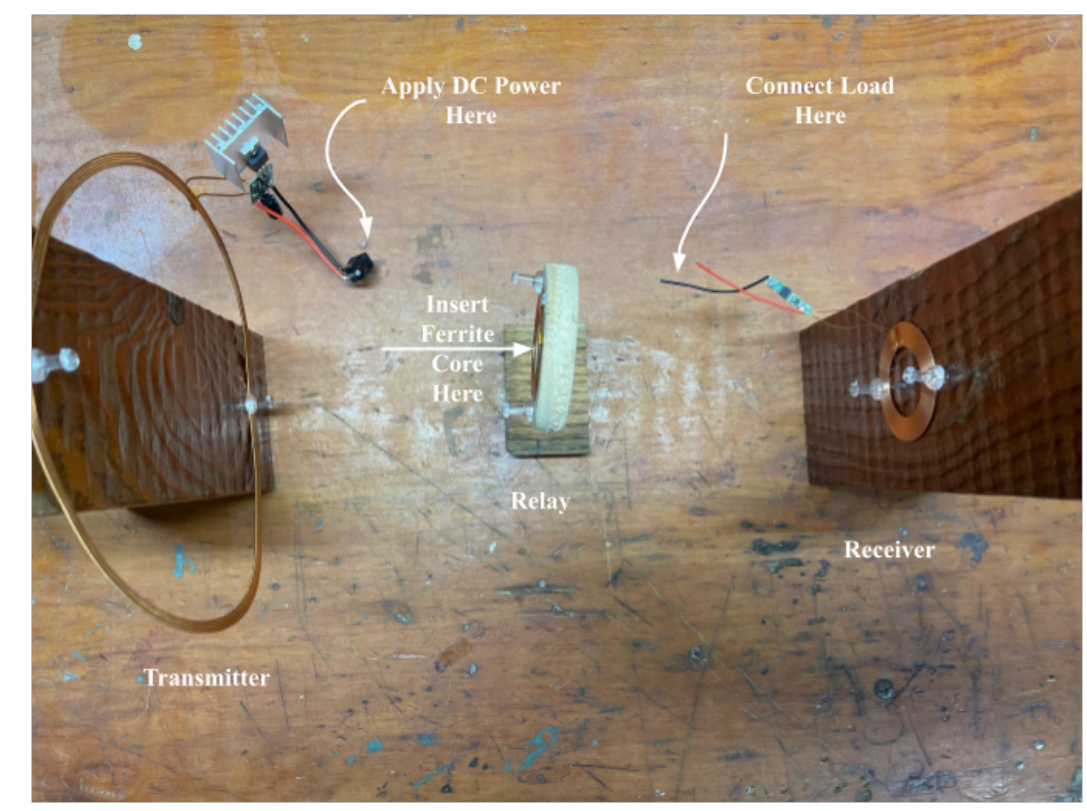

Fig. 4: The Experimental Setup of WPT System. Note that the coils are mounted such that they are all concentric, and distance between coils is changed by simply relocating a module along a coaxial line. 


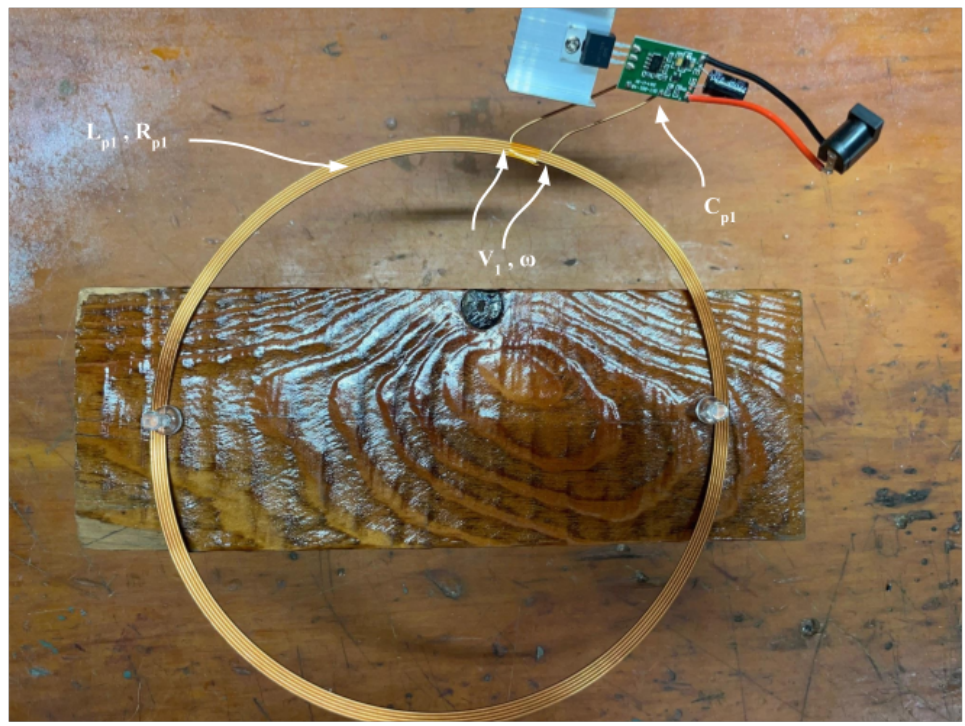

Fig. 5: The Experimental Transmitter (TX) Setup. Note that parameters indicated were measured to be $L_{p 1}=15.3 \mu H, R_{p 1}=0.5 \Omega$, $C_{p 1}=20.7 n F$.

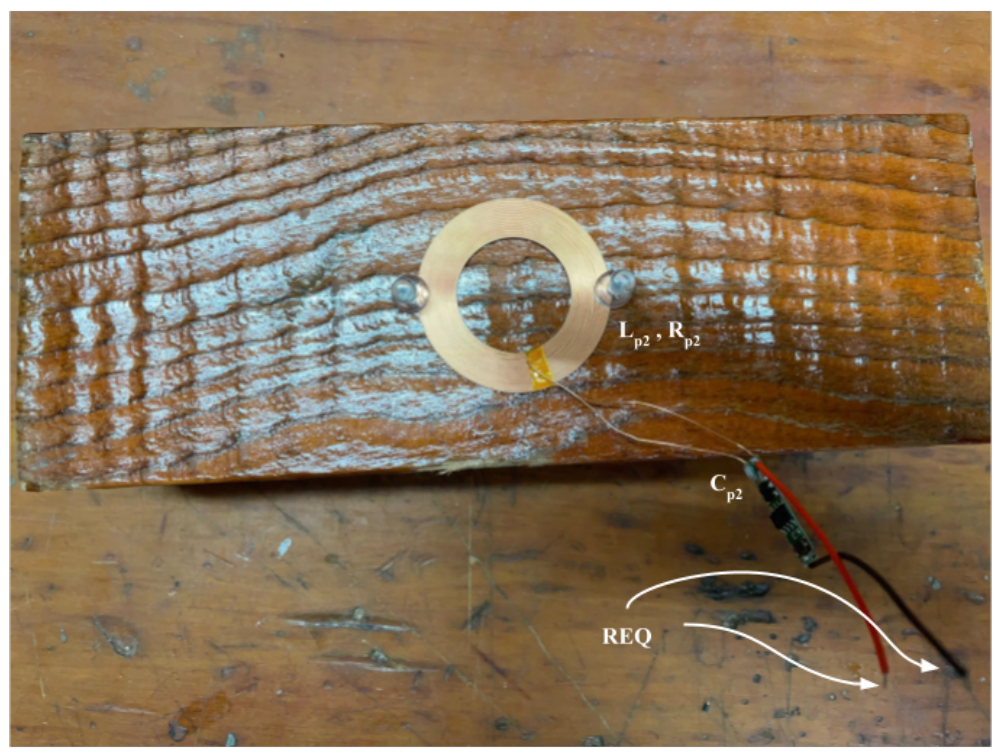

Fig. 6: The Experimental Receiver (RX) Setup. Note that parameters indicated were measured to be $L_{p 2}=50.9 \mu H, R_{p 2}=0.9 \Omega$, $C_{p 2}=15.5 n F$ 


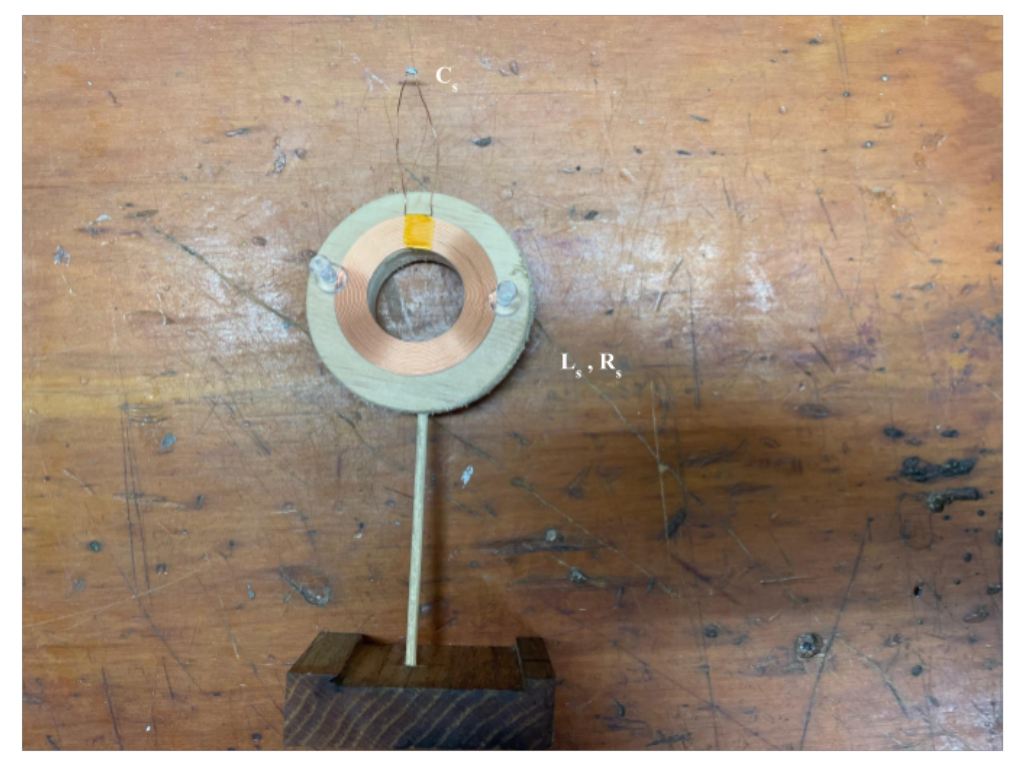

Fig. 7: The Experimental Air-Core Relay Setup. Note that parameters indicated were measured to be $L_{s}=50.9 \mu H, R_{s}=0.9 \Omega$, $C_{s}=15.5 n F$

$\mathrm{m} 1$

freq $=182.0 \mathrm{kHz}$

$\mathrm{dB}($ ACRel.. S $(2,1))=-38.696$

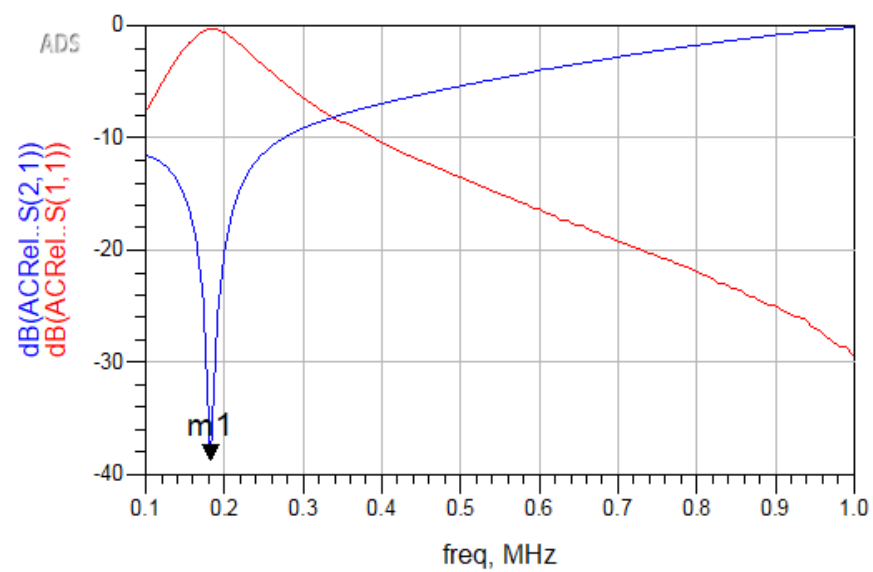

Fig. 8: The Resonance of the Experimental Air-Core Relay Setup. Note that the actual Taidacent WPT system operates at $182 \mathrm{kHz}$ and not $215 \mathrm{kHz}$ as the datasheet parameters imply. 


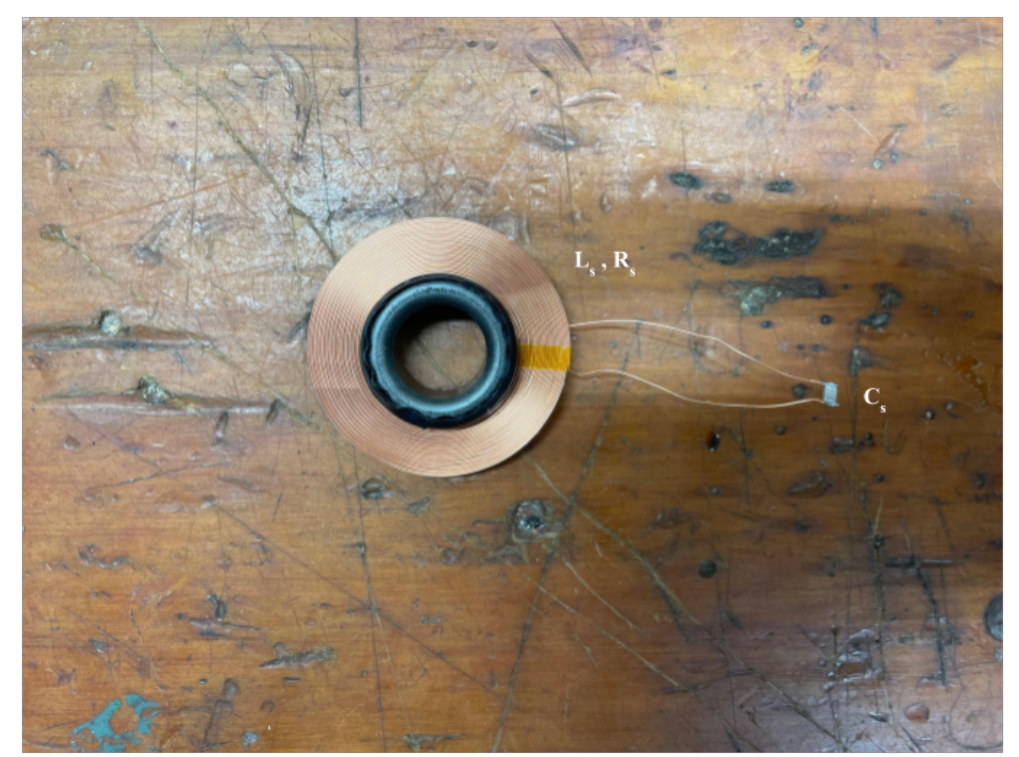

Fig. 9: The Experimental Ferrite-Core Relay Setup. Note that parameters indicated were measured to be $L_{s}=75 \mu H, R_{s}=0.9 \Omega$, $C_{s}=10.4 n F$

$\mathrm{m} 2$

freq $=182.0 \mathrm{kHz}$

$\mathrm{dB}($ FCRel..S $(2,1))=-46.196$

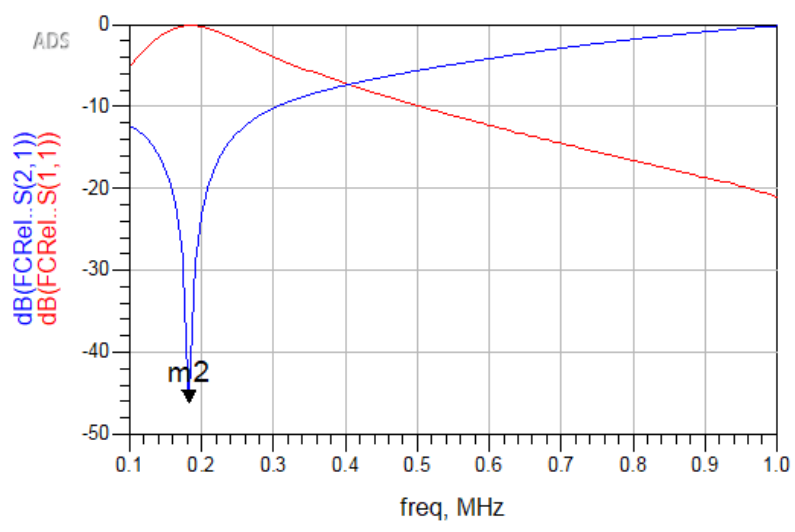

Fig. 10: The Resonance of the Experimental Ferrite-Core Relay Setup. Note that the actual Taidacent WPT system operates at $182 \mathrm{kHz}$ and not $215 \mathrm{kHz}$ as the datasheet parameters imply. 


\section{III-A Experimental Procedure}

The procedure for the experiments goes as follows:

- For both air-core and ferrite-core systems,

- Start by setting TX and RX $20 \mathrm{~cm}$ apart and concentric.

- Set the relay concentrically between TX and RX.

- For each load,

* Measure the output voltage and determine the optimal position of the relay coil between the receiver and transmitter for maximum output voltage.

* Record voltage and calculate output power.

- Repeat for distances of $40 \mathrm{~cm}, 60 \mathrm{~cm}, 80 \mathrm{~cm}$, and $100 \mathrm{~cm}$.

\section{III-B Experimental Data}

\begin{tabular}{|c|c|c|c|c|c|}
\hline & Configuration \#1 & Configuration \#2 & Configuration \#3 & Configuration \#4 & Configuration \#5 \\
\hline $\mathbf{1} \Omega\left(d_{23}=0.015 \mathbf{m}\right)$ & 2110 & 91.1 & 78.1 & 50 & 50 \\
\hline $\mathbf{1 0} \Omega\left(d_{23}=0.015 \mathbf{m}\right)$ & 3380 & 101 & 15.3 & 7.20 & 5 \\
\hline $\mathbf{1 0 0} \Omega\left(d_{23}=0.02 \mathbf{m}\right)$ & 19000 & 392 & 36.1 & 9.03 & 3.12 \\
\hline $\mathbf{1 0 0 0} \Omega\left(d_{23}=0.04 \mathbf{m}\right)$ & 56100 & 994 & 74.1 & 13.6 & 4.05 \\
\hline $\mathbf{1 0 0 0 0} \Omega\left(d_{23}=0.05 \mathbf{m}\right)$ & 27600 & 492 & 36.1 & 6.12 & 1.62 \\
\hline $\mathbf{1 0 0 0 0 0} \Omega\left(d_{23}=0.05 \mathbf{m}\right)$ & 3590 & 63 & 4.80 & 0.882 & 0.22 \\
\hline $\mathbf{1 0 0 0 0 0 0} \Omega\left(d_{23}=0.05 \mathbf{m}\right)$ & 364 & 6.48 & 0.5 & 0.0903 & 0.0231 \\
\hline
\end{tabular}

TABLE V: Experimental Air-Core Data in $[\mu \mathrm{W}]$

\begin{tabular}{|c|c|c|c|c|c|}
\hline & Configuration \#1 & Configuration \#2 & Configuration \#3 & Configuration \#4 & Configuration \#5 \\
\hline $\mathbf{1} \Omega\left(d_{23}=0.015 \mathbf{m}\right)$ & 4510 & 112 & 12.5 & 72.0 & 50 \\
\hline $\mathbf{1 0} \Omega\left(d_{23}=0.015 \mathbf{m}\right)$ & 6120 & 151 & 5.00 & 7.20 & 5 \\
\hline $\mathbf{1 0 0} \Omega\left(d_{23}=0.03 \mathbf{m}\right)$ & 40600 & 648 & 60.5 & 12.5 & 3.8 \\
\hline $\mathbf{1 0 0 0} \Omega\left(d_{23}=0.05 \mathbf{m}\right)$ & 123000 & 1710 & 151 & 24.2 & 6.6 \\
\hline $\mathbf{1 0 0 0 0} \Omega\left(d_{23}=0.05 \mathbf{m}\right)$ & 64800 & 1080 & 81.9 & 15.1 & 3.5 \\
\hline $\mathbf{1 0 0 0 0 0} \Omega\left(d_{23}=0.05 \mathbf{m}\right)$ & 9240 & 140 & 11.2 & 1.95 & 0.47 \\
\hline $\mathbf{1 0 0 0 0 0 0} \Omega\left(d_{23}=0.05 \mathbf{m}\right)$ & 946 & 15.1 & 1.12 & 0.198 & 0.048 \\
\hline
\end{tabular}

TABLE VI: Experimental Ferrite-Core Data in $[\mu \mathrm{W}]$ 


\section{Results}

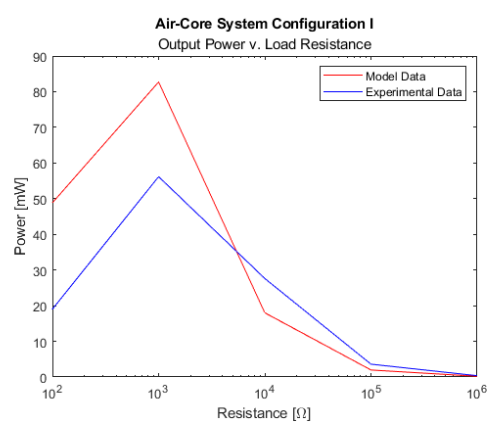

(a)

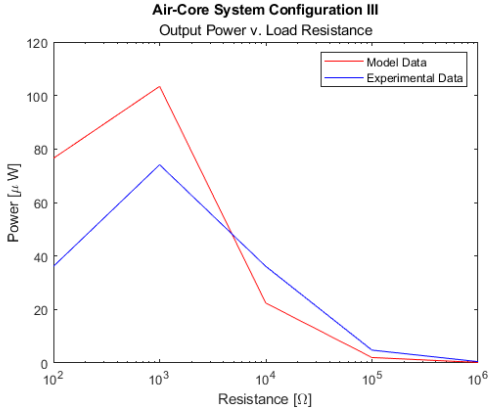

(c)

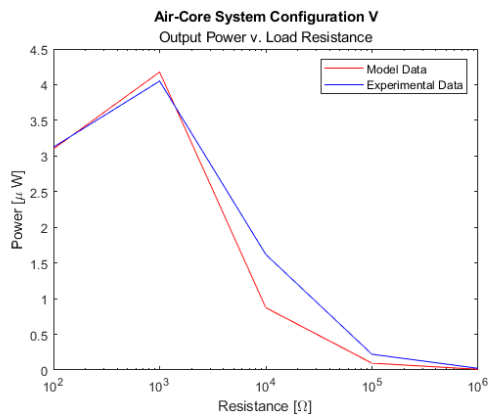

(e)

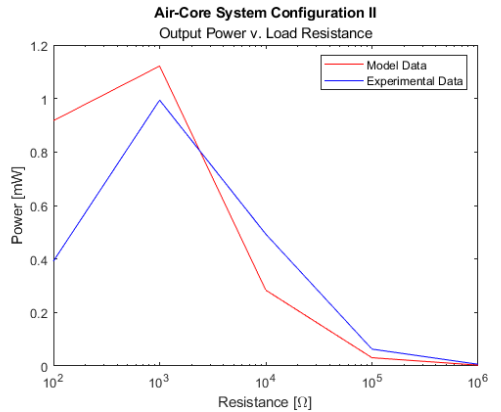

(b)

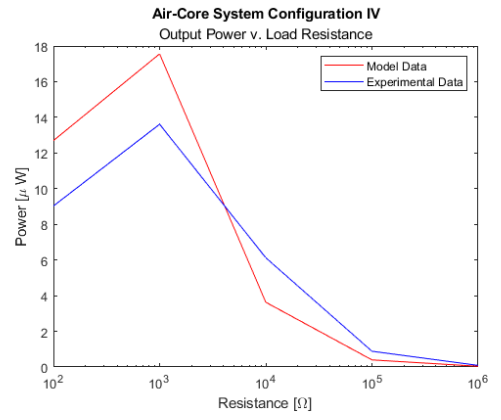

(d)

Fig. 11: Output Power Characteristics of the Air-Core-Relay WPT System 


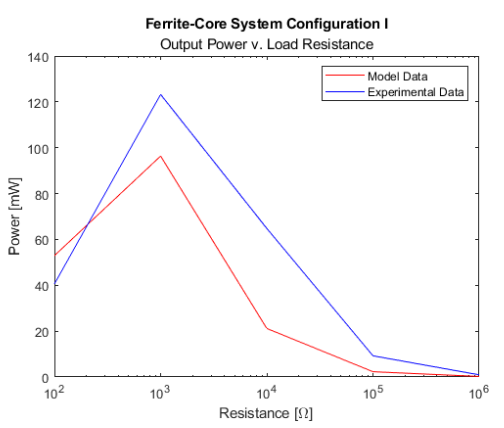

(a)

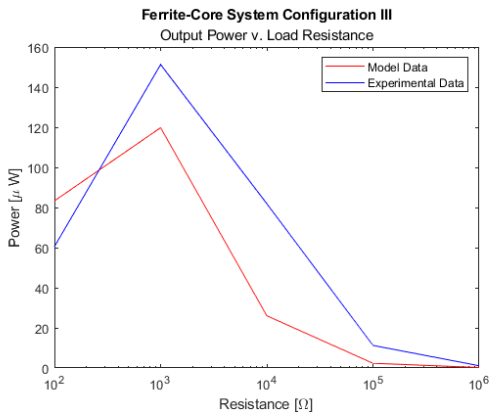

(c)

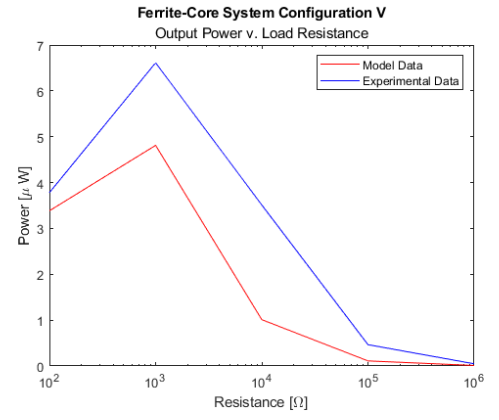

(e)

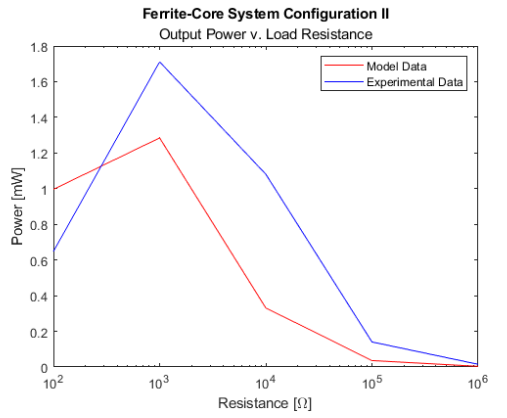

(b)

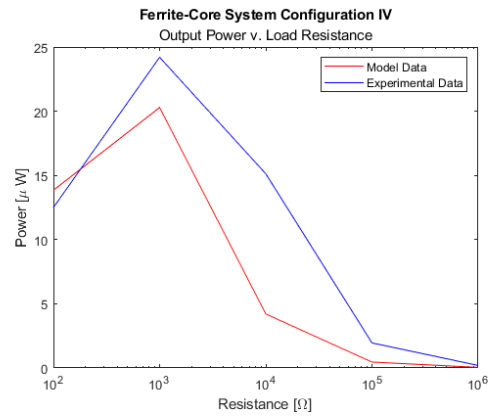

(d)

Fig. 12: Output Power Characteristics of the Ferrite-Core-Relay WPT System 


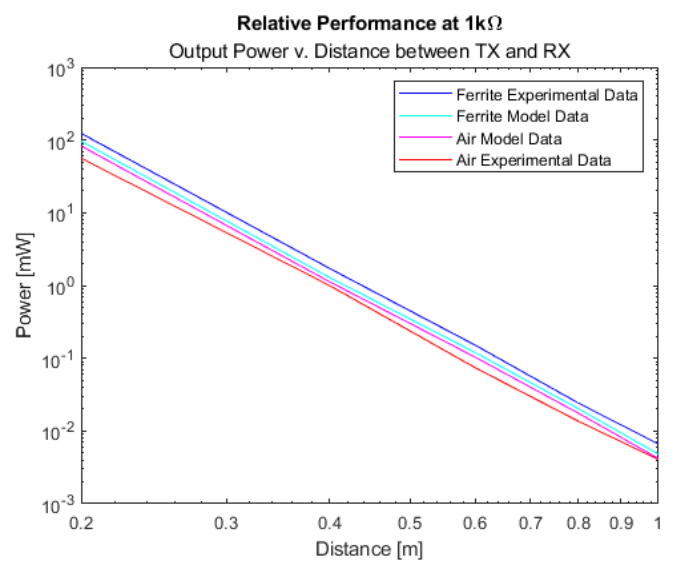

Fig. 13: The Relative Performance of Air-Core and Ferrite-Core at $1 \mathrm{k} \Omega$ 


\section{Discussion and Conclusion}

\section{V-A Comparison of Model and Experiment}

Overall, it may be concluded from Fig. 11 and Fig. 12 that the mathematical model employed in this thesis adequately approximates the output power characteristics of both air-core-relay and ferrite-corerelay WPT systems. In the case of the air-core-relay system, the theoretical maximum output power is larger than that measured for each distance configuration. This is most probably due to inaccurate model estimates of circuit resistances. Furthermore, as the transmission distance increases, low-resistance loads yield output powers that are below the noise floor of the oscilloscope, so the measurements are inaccurate at these points. As a result, data for $1 \Omega$ and $10 \Omega$ loads are omitted in Fig. 11 and Fig. 12. Overall, the model error for each load averaged over all distance configurations is as follows,

\begin{tabular}{|c|c|c|c|c|c|c|}
\hline $1 \Omega$ & $10 \Omega$ & $100 \Omega$ & $1000 \Omega$ & $10000 \Omega$ & $100000 \Omega$ & $1000000 \Omega$ \\
\hline$-7427.6 \%$ & $-14.3 \%$ & $39.8 \%$ & $19.5 \%$ & $-68.6 \%$ & $-115.1 \%$ & $-120.1 \%$ \\
\hline
\end{tabular}

TABLE VII: Air-Core Model Error for Each Load, Averaged Over All Distance Configurations.

In the case of the ferrite-core system, the theoretical maximum output power is generally smaller than that measured, which is probably due to the fact that the model does not accurately represent the increase in mutual inductance due to flux concentration in the ferrite core. After all, the model used in this thesis is technically not the full model developed in [11], where equation (10) presented in this paper would contain an extra term $\left(\frac{l_{C_{\text {ore }}}{ }^{2}}{w_{\text {Rel. }}^{2}}\right)^{\frac{1}{3}}$ to account for the increase in flux density within the relay coil due to a long ferrite core. Again, as the transmission distance increases, low-resistance loads yield power outputs that are below the noise floor of the oscilloscope, so the measurements are inaccurate at these points. As a result, data for $1 \Omega$ and $10 \Omega$ loads are omitted in Fig. 11 and Fig. 12. Overall, the average error for each load was as follows,

\begin{tabular}{|c|c|c|c|c|c|c|}
\hline $1 \Omega$ & $10 \Omega$ & $100 \Omega$ & $1000 \Omega$ & $10000 \Omega$ & $100000 \Omega$ & $1000000 \Omega$ \\
\hline$-7582.8 \%$ & $-8.5 \%$ & $16.7 \%$ & $-28.8 \%$ & $-230.9 \%$ & $-322.8 \%$ & $-331.1 \%$ \\
\hline
\end{tabular}

TABLE VIII: Ferrite-Core Model Error for Each Load, Averaged Over All Distance Configurations. 


\section{V-B Comparison of Systems}

Upon comparing Fig. 11 and Fig. 12, the ultimate conclusion is that the addition of a ferrite core noticeably improves the output power for a given load and distance configuration. Overall, the average improvement to output power for each load as a result of using a ferrite core instead of an air core is as follows,

\begin{tabular}{|c|c|c|c|c|c|c|}
\hline $1 \Omega$ & $10 \Omega$ & $100 \Omega$ & $1000 \Omega$ & $10000 \Omega$ & $100000 \Omega$ & $1000000 \Omega$ \\
\hline $20 \%$ & $10 \%$ & $60 \%$ & $90 \%$ & $130 \%$ & $130 \%$ & $130 \%$ \\
\hline
\end{tabular}

TABLE IX: Percent Increase in Output Power When Switching from Air-Core Relay to Ferrite-Core Relay for Each Load, Averaged Over All Distance Configurations. Note that the apparent improvement at $1 \Omega$ and $10 \Omega$ loads is inaccurate due to noise floor issues.

The results shown in Table IX corroborate the theory embedded in equation (1). For intuition, assume the following ultra-simplified math model,

$$
\left[\begin{array}{c}
V_{1} \\
0 \\
0
\end{array}\right]=\left[\begin{array}{ccc}
j \omega L_{p 1} & 0 & 0 \\
j \omega M_{21} & 0 & 0 \\
0 & j \omega M_{32} & j \omega L_{p 2}+R E Q \| \frac{-j}{\omega C_{p 2}}
\end{array}\right]\left[\begin{array}{c}
I_{1} \\
I_{2} \\
I_{3}
\end{array}\right]
$$

Where the following simplifications have been made:

- Inductor series resistances $R_{p 1}, R_{s}$, and $R_{p 2}$ are approximated as zero since inductors are nearly perfect DC short circuits.

- The effects of $I_{2} \times j \omega M_{12}, I_{3} \times j \omega M_{13}, I_{3} \times j \omega M_{23}$ and $I_{1} \times j \omega M_{31}$ are approximated as zero because very low inductive coupling is assumed.

Then, the current in the inductor of the receiver can be modeled as,

$$
I_{3}=\frac{\frac{V_{1} M_{21}}{L_{p 1}}-j \omega M_{32} I_{2}}{j \omega L_{p 2}+R E Q \| \frac{-j}{\omega C_{p 2}}}
$$

Now, both $M_{21}$ and $M_{32}$ are multiplied by a factor, $k$ (see equation (9)), when a ferrite core is introduced. Since this is a common factor, $I_{3}$ is roughly proportional to the change in mutual inductance caused by the ferrite core. Additionally, since power is proportional to the square of the current, the power is roughly proportional to the square of the change in mutual inductance.

Also, from Table IX, we can note that the improvement to output power is more pronounced at higher resistances. However, as seen in Fig. 11 and Fig. 12, maximum power transfer for both air-core and ferrite-core systems occurs at around $1000 \Omega$. Therefore, there must be a compromise between power output improvement and the size of the resistive load.

From Fig. 13, we can see that, assuming optimal positioning of the relay and constant load, the relationship between output power $(\mathrm{P})$ and the distance between transmitter and receiver (D) is of the following forms:

$$
P=k D^{n}
$$




$$
\log P=\log k+n \log D
$$

Furthermore, we can determine the value of $k$ and $n$ graphically, yielding the following equations for the air-core-relay system and the ferrite-core relay system at $1000 \Omega$,

$$
\begin{gathered}
P_{\text {AirCore }}=\left(4.1 \times 10^{-6}\right) D^{-5.9} \mathrm{~W} \\
P_{\text {FerriteCore }}=\left(6.6 \times 10^{-6}\right) D^{-6.1} \mathrm{~W}
\end{gathered}
$$

\section{V-C Future of Research}

These facts open up many opportunities for further investigation. Future experiments could attempt to directly power an actual wearable device such as a low-power remote sensor. Furthermore, experiments on the addition of ferrite cores to the TX coil and the RX coil could also be performed to see if power output characteristics are further improved. 


\section{Appendix: Datasheets}

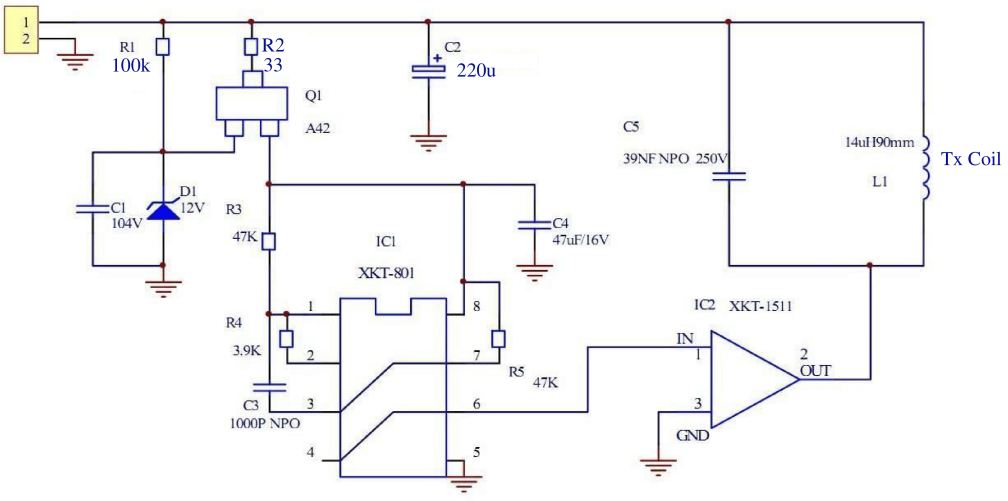

Fig. 14: Datasheet for the Taidacent Transmitter

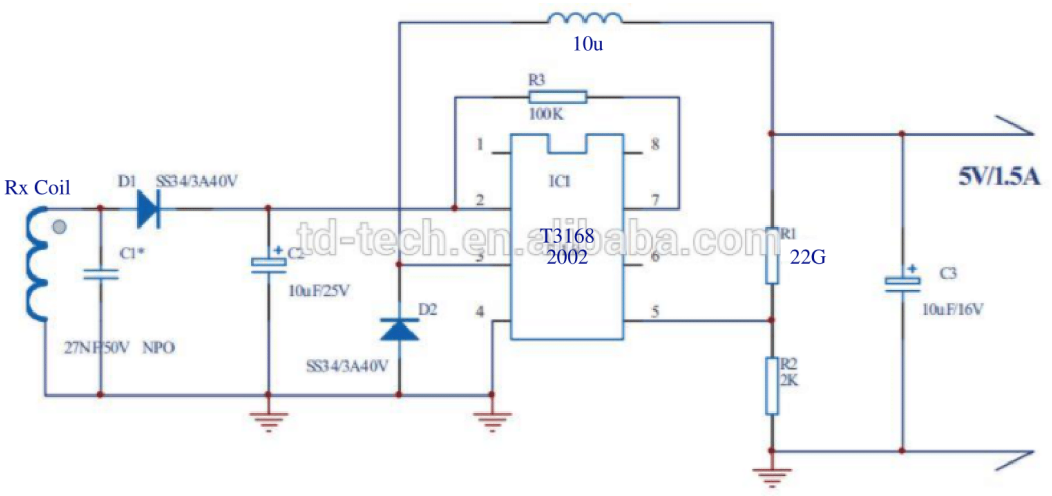

Fig. 15: Datasheet for the Taidacent Receiver. Note that the only part used in this thesis is the "Rx Coil" in parallel with "C1*". The diode "D1" is desoldered and so LC circuit is disconnected from the rest of the circuit. 


\section{Appendix: MATLAB Code}

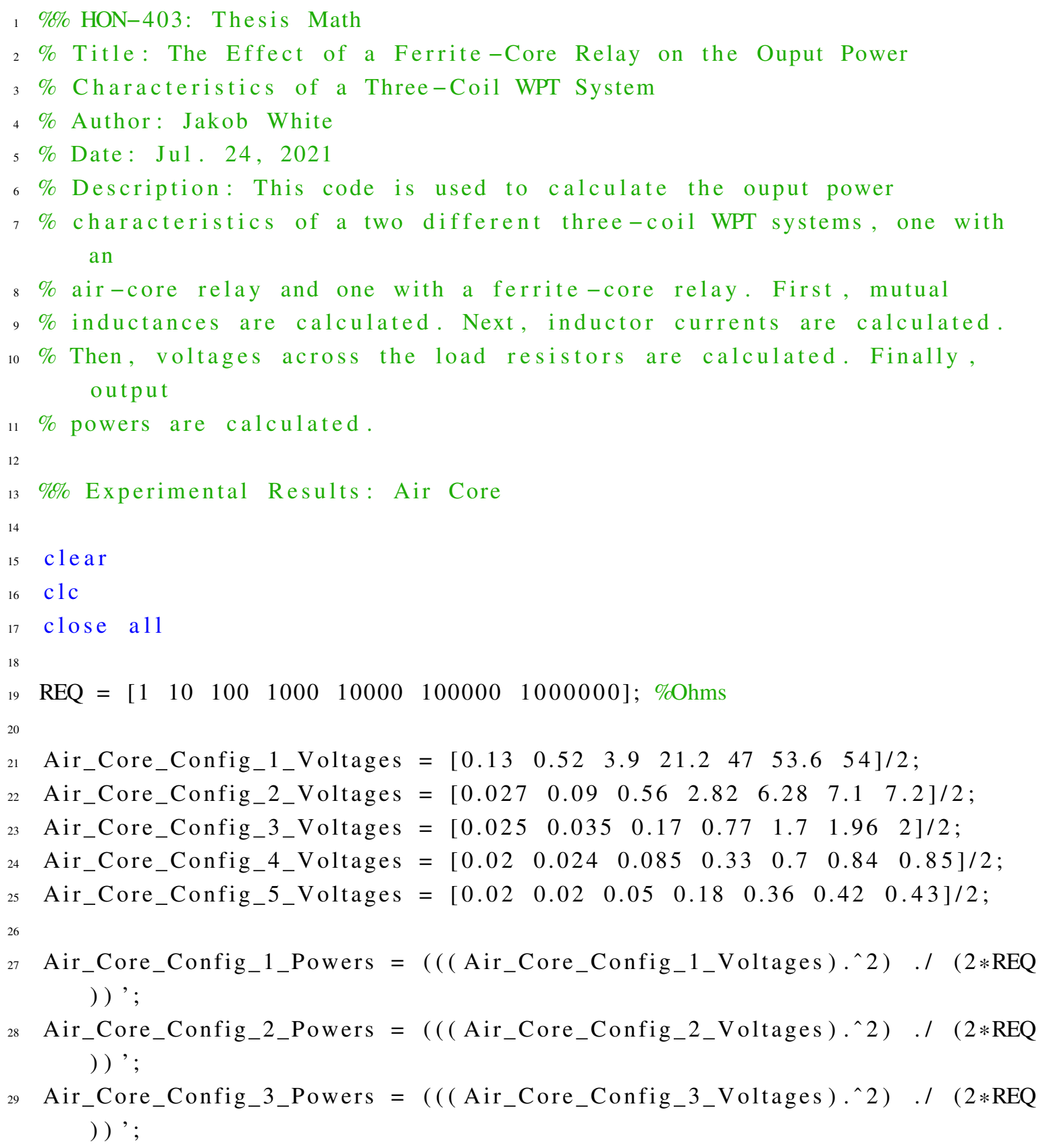


30

53

56 Two_Coil_Config_1_Voltages $=\left[\begin{array}{lllllll}0.07 & 0.2 & 1.38 & 9.36 & 16.2 & 17.4 & 17.4\end{array}\right] / 2 ;$

57 Two_Coil_Config_2_Voltages $=\left[\begin{array}{llllllll}0.02 & 0.04 & 0.21 & 1.3 & 2.4 & 2.5 & 2.5\end{array}\right] / 2$;

Air_Core_Config_4_Powers $=\left(\left((\right.\right.$ Air_Core_Config_4_Voltages $\left.) .{ }^{\wedge} 2\right) . /(2 *$ REQ ) )';

Air_Core_Config_5_Powers $=\left(\left((\right.\right.$ Air_Core_Config_5_Voltages $\left.) .^{\wedge} 2\right) . /(2 * R E Q$ ) )';

$\%$ Experimental Results: Ferrite Core

Ferrite_Core_Config_1_Voltages $=\left[\begin{array}{lllllll}0.19 & 0.7 & 5.7 & 31.4 & 72 & 86 & 87\end{array}\right]$;

Ferrite_Core_Config_2_Voltages $=\left[\begin{array}{lllllll}0.03 & 0.11 & 0.72 & 3.7 & 9.3 & 10.6 & 11\end{array}\right] / 2$;

Ferrite_Core_Config_3_Voltages $=\left[\begin{array}{lllllll}0.01 & 0.02 & 0.22 & 1.1 & 2.56 & 3 & 3\end{array}\right] / 2$;

Ferrite_Core_Config_4_Voltages $=\left[\begin{array}{lllllll}0.024 & 0.024 & 0.1 & 0.44 & 1.1 & 1.25\end{array}\right.$ $1.26] / 2$;

Ferrite_Core_Config_5_Voltages $=\left[\begin{array}{llllll}0.02 & 0.02 & 0.055 & 0.23 & 0.53 & 0.61\end{array}\right.$ $0.62] / 2$;

Ferrite_Core_Config_1_Powers $=((($ Ferrite_Core_Config_1_Voltages $) . \wedge 2)$ . / (2*REQ) )';

Ferrite_Core_Config_2_Powers $=\left(\left((\right.\right.$ Ferrite_Core_Config_2_Voltages $\left.) .^{\wedge} 2\right)$ ./ (2*REQ) )';

Ferrite_Core_Config_3_Powers $=\left(\left((\right.\right.$ Ferrite_Core_Config_3_Voltages $\left.) .^{\wedge} 2\right)$ ./ $(2 * \mathrm{REQ}))^{\prime}$;

Ferrite_Core_Config_4_Powers $=\left(\left((\right.\right.$ Ferrite_Core_Config_4_Voltages $\left.) .^{\wedge} 2\right)$ . / (2*REQ) )';

Ferrite_Core_Config_5_Powers $=\left(\left((\right.\right.$ Ferrite_Core_Config_5_Voltages $\left.) .{ }^{\wedge} 2\right)$ . / $(2 * \mathrm{REQ}))$ ';

Power_Imp_1 = Ferrite_Core_Config_1_Powers ./ Air_Core_Config_1_Powers; Power_Imp_2 = Ferrite_Core_Config_2_Powers ./ Air_Core_Config_2_Powers; Power_Imp_3 = Ferrite_Core_Config_3_Powers ./ Air_Core_Config_3_Powers; Power_Imp_4 = Ferrite_Core_Config_4_Powers ./ Air_Core_Config_4_Powers; Power_Imp_5 = Ferrite_Core_Config_5_Powers ./ Air_Core_Config_5_Powers;

Avg_Power_Imp $=($ Power_Imp_1 + Power_Imp_2 + Power_Imp_3 + Power_Imp_4 + Power_Imp_5) / 5;

$\%$ Experimental Results: Two-Coil System 


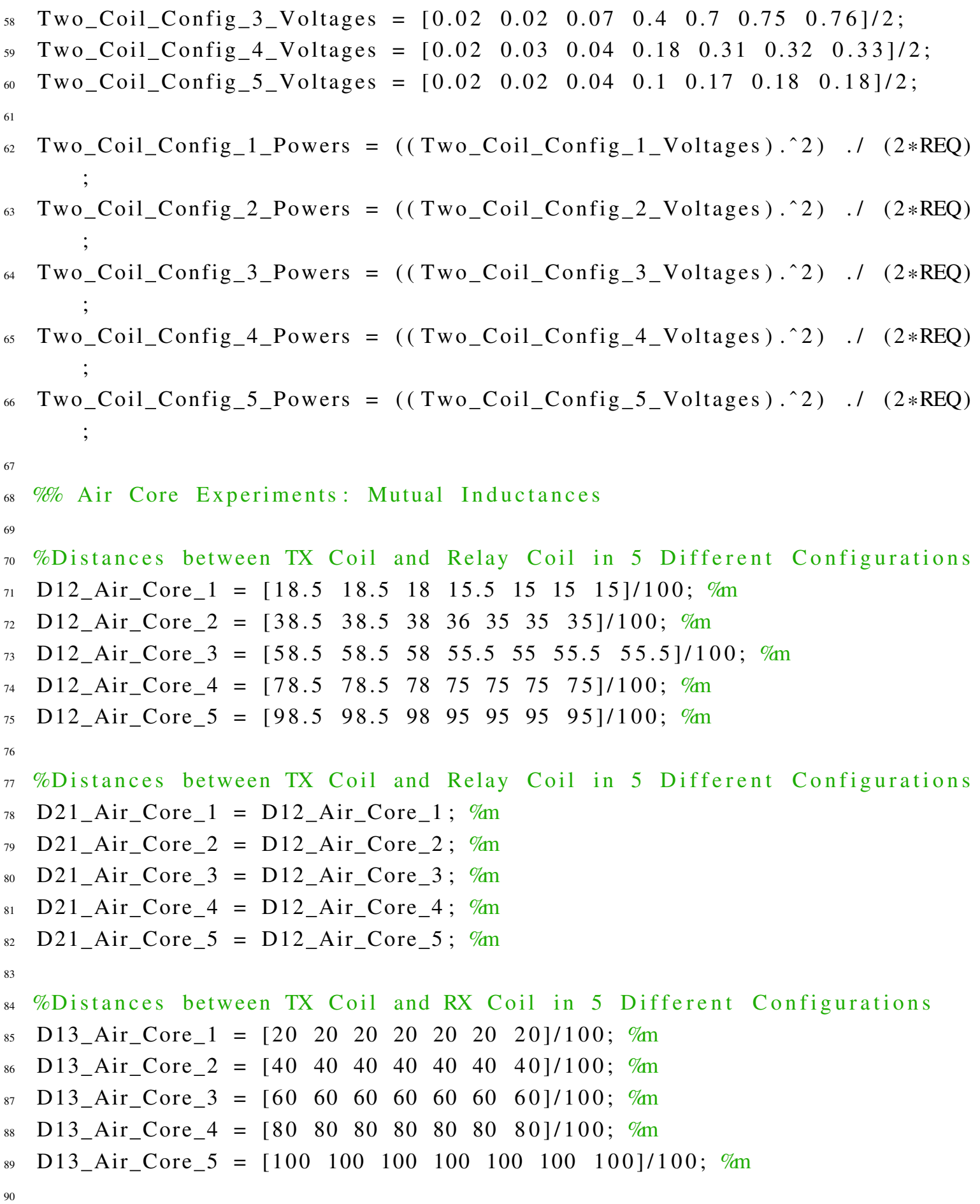




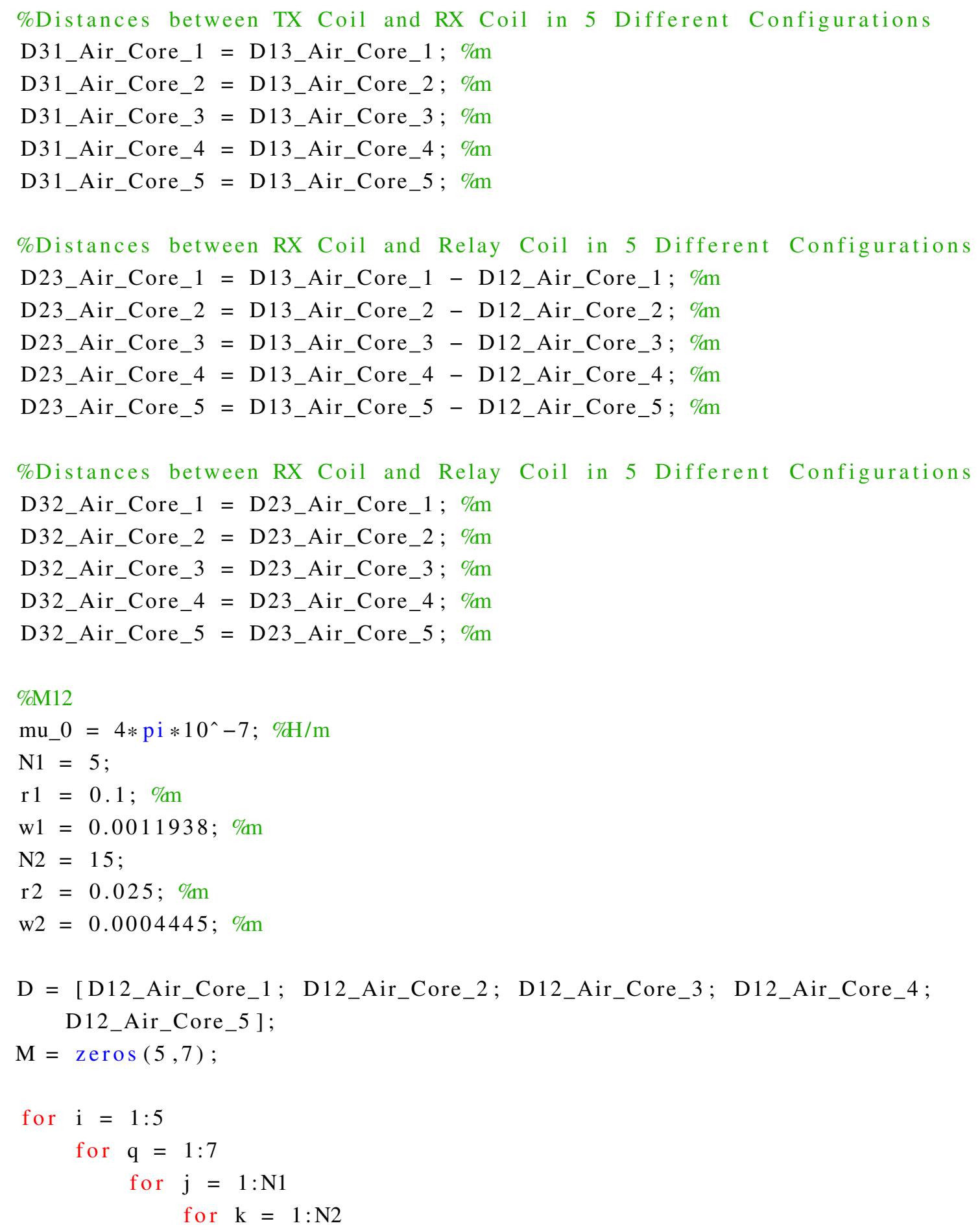




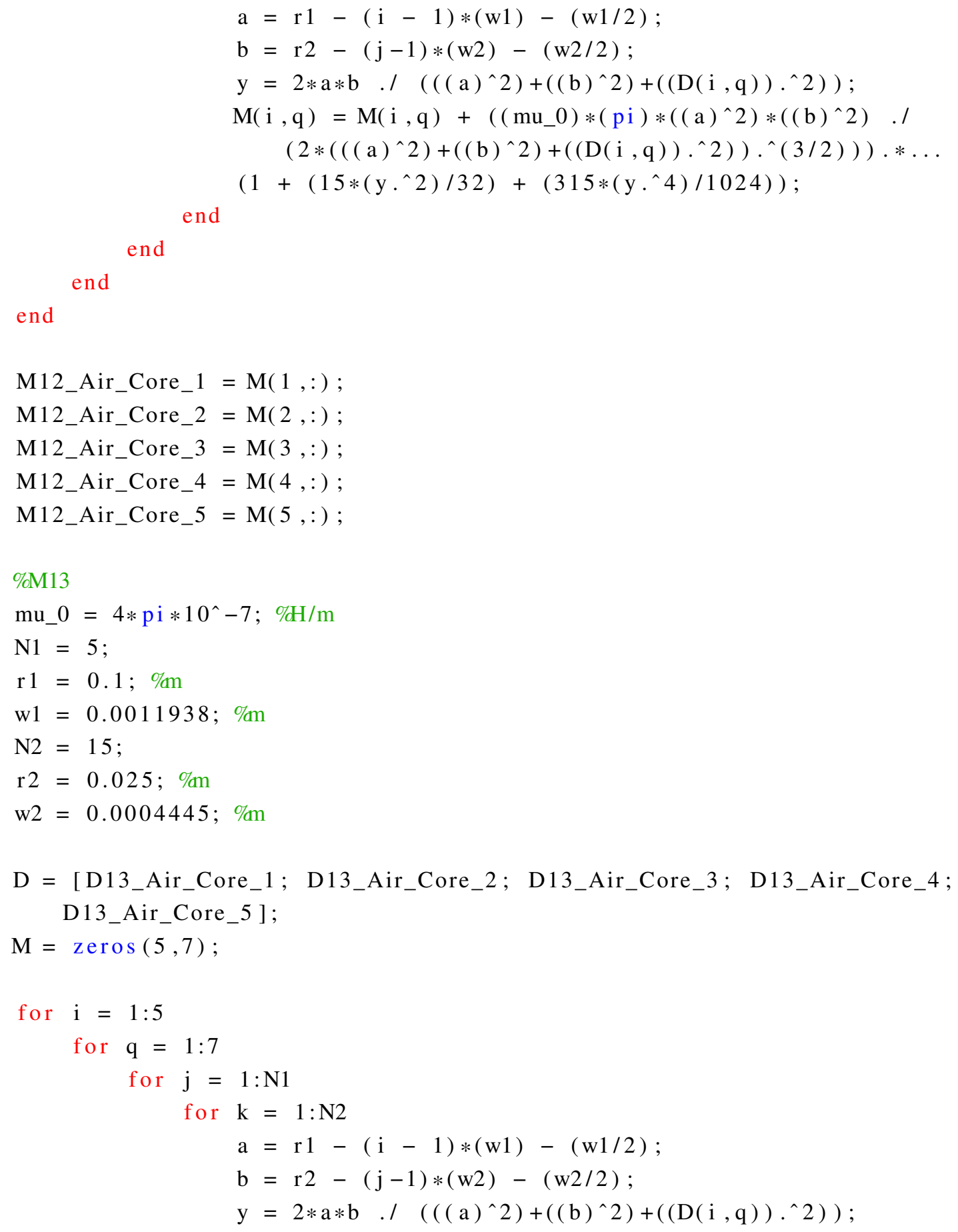




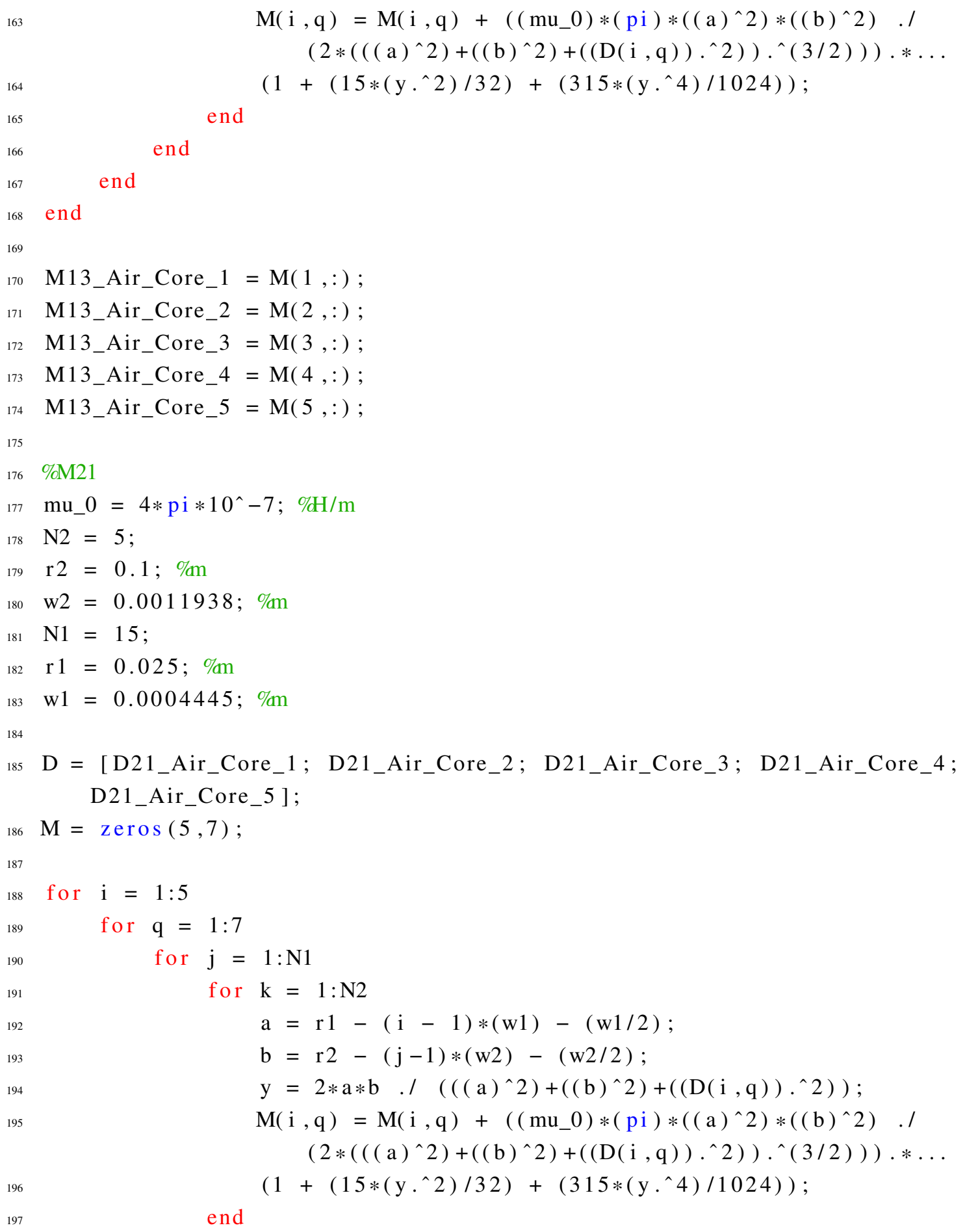




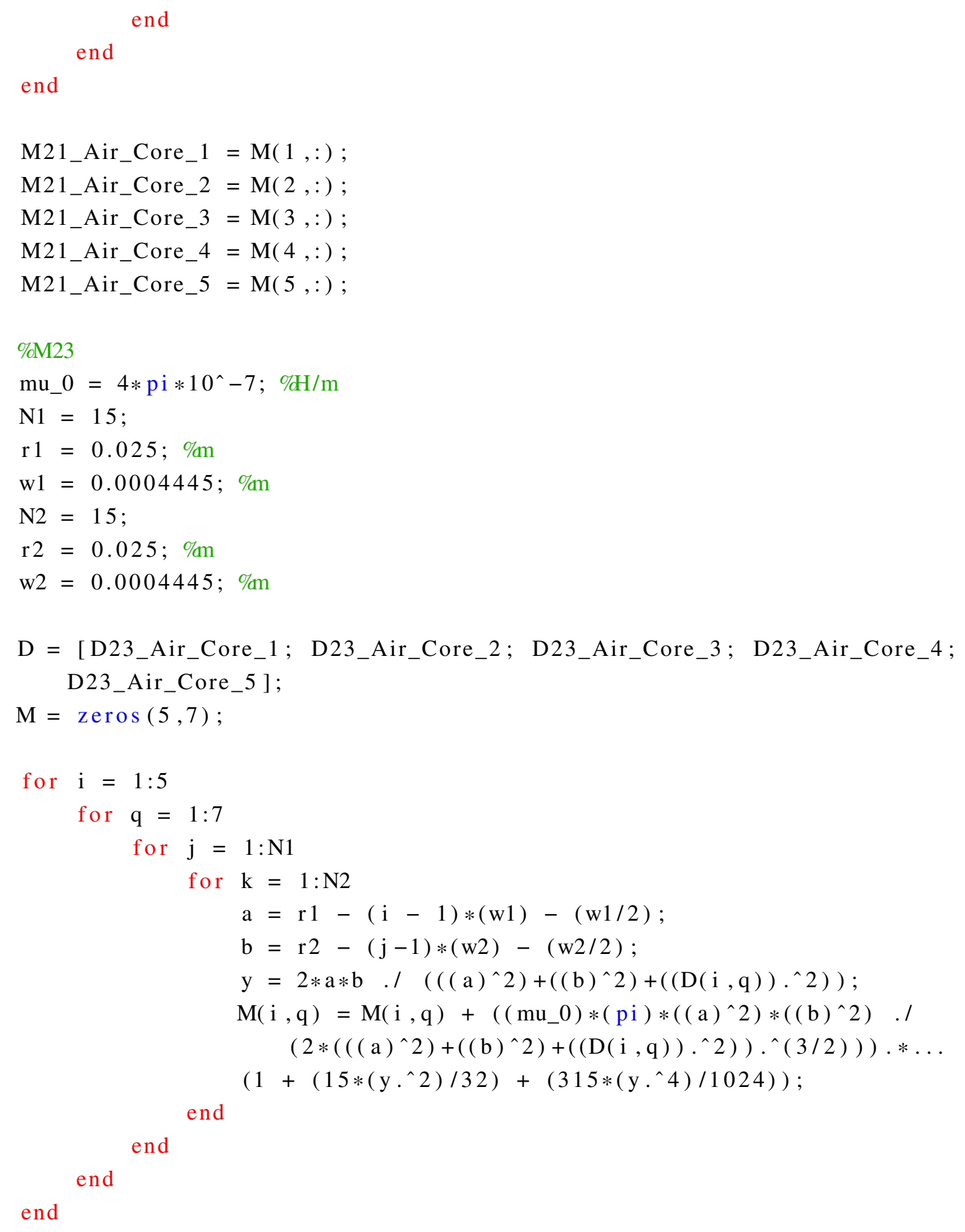




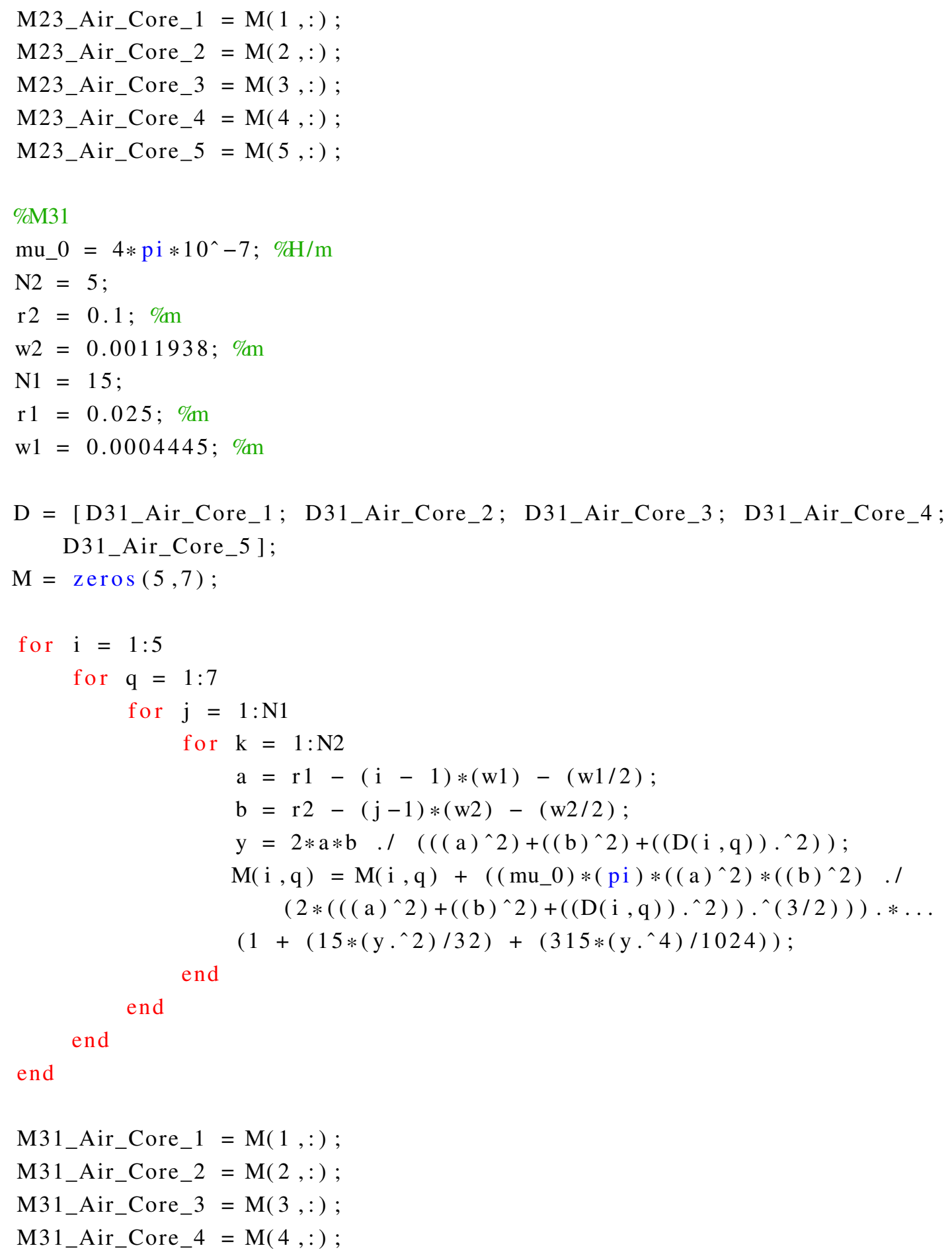




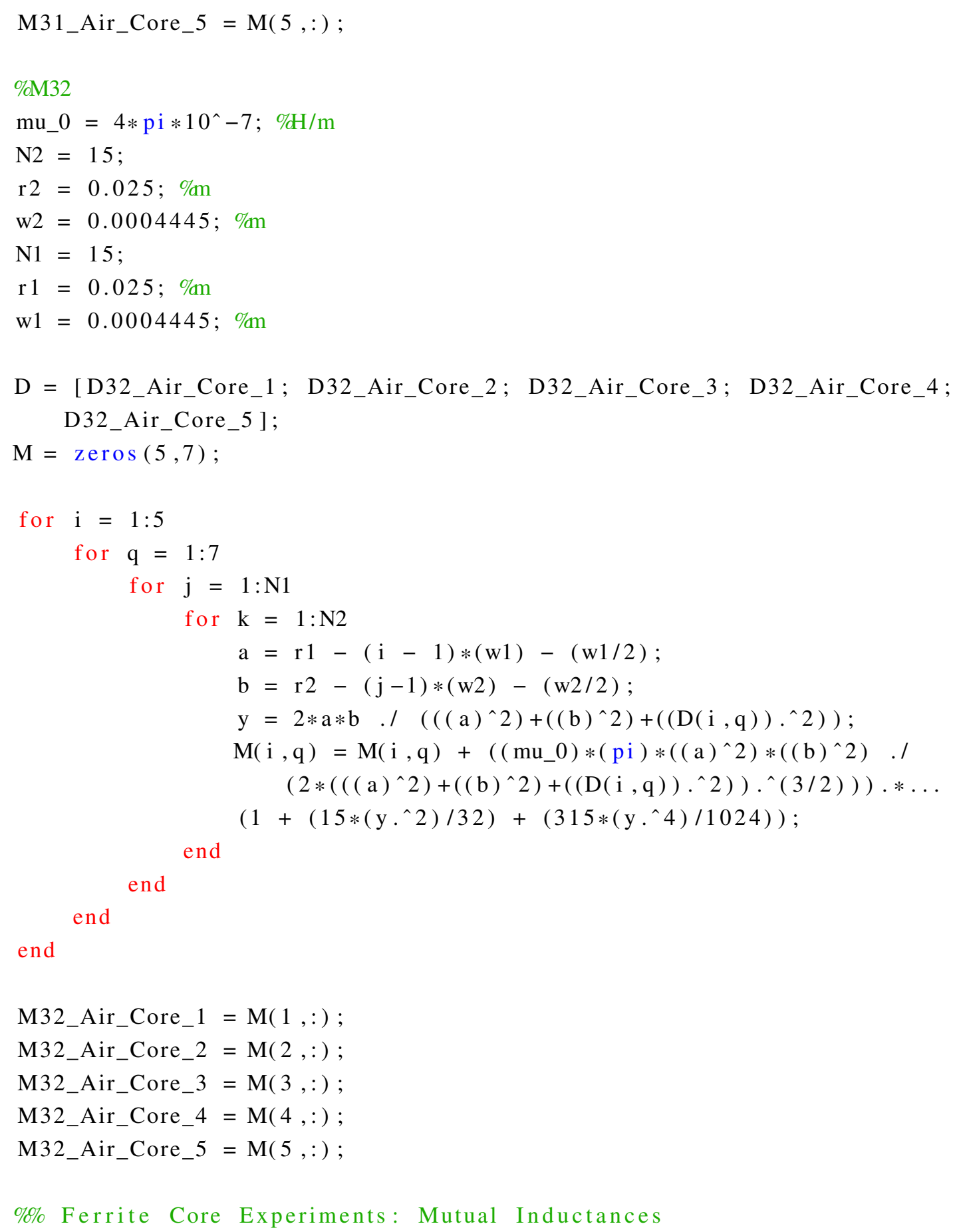




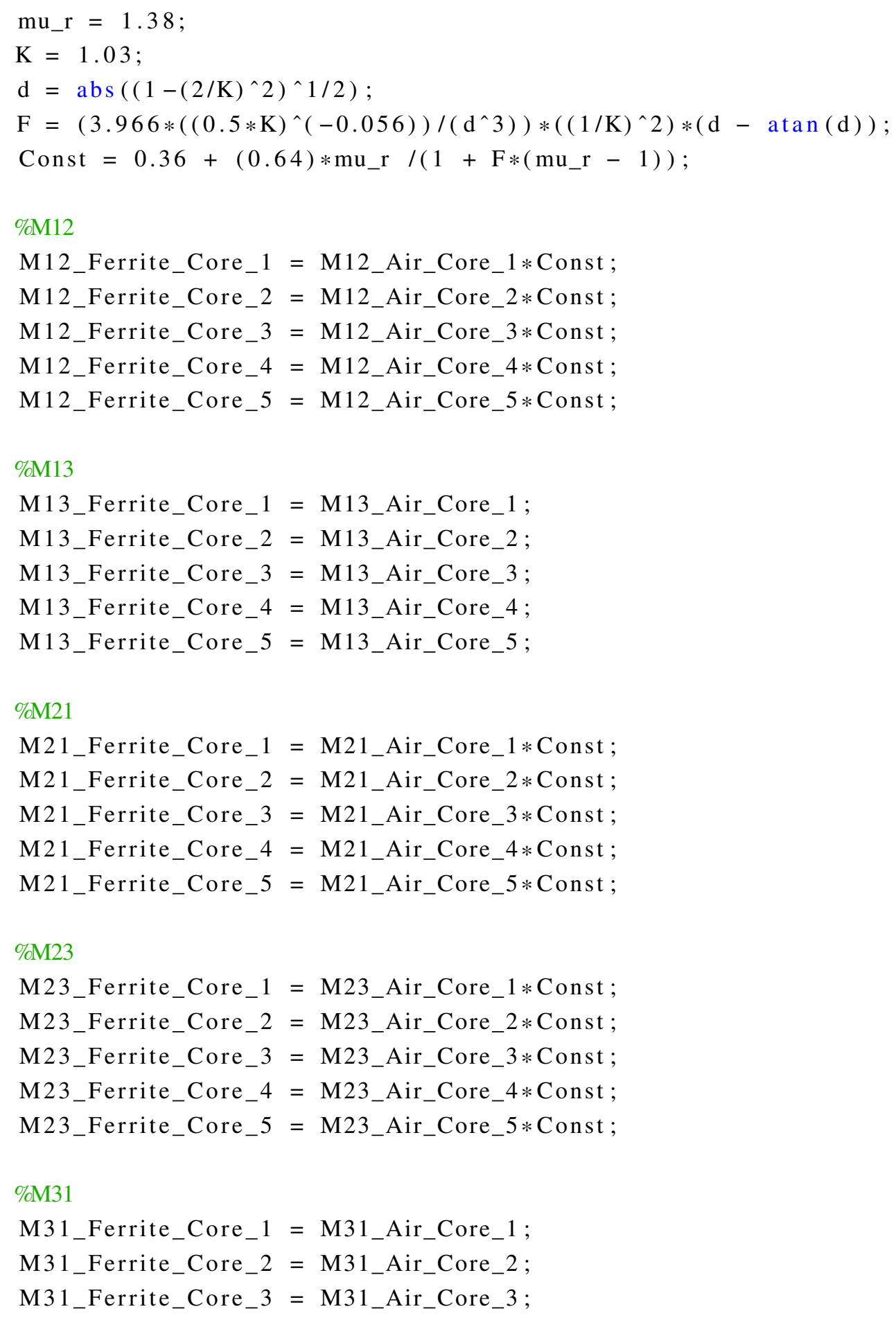




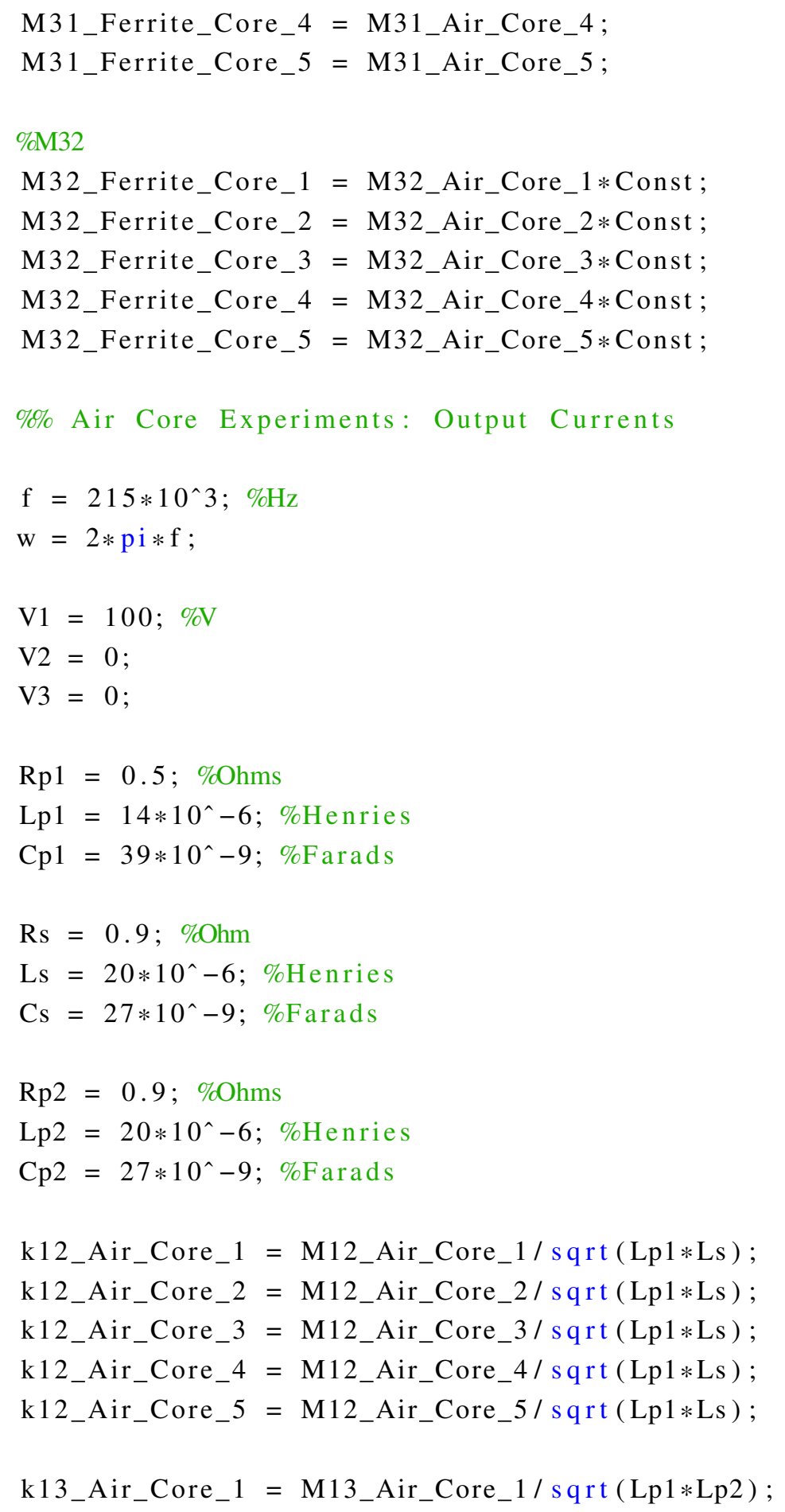




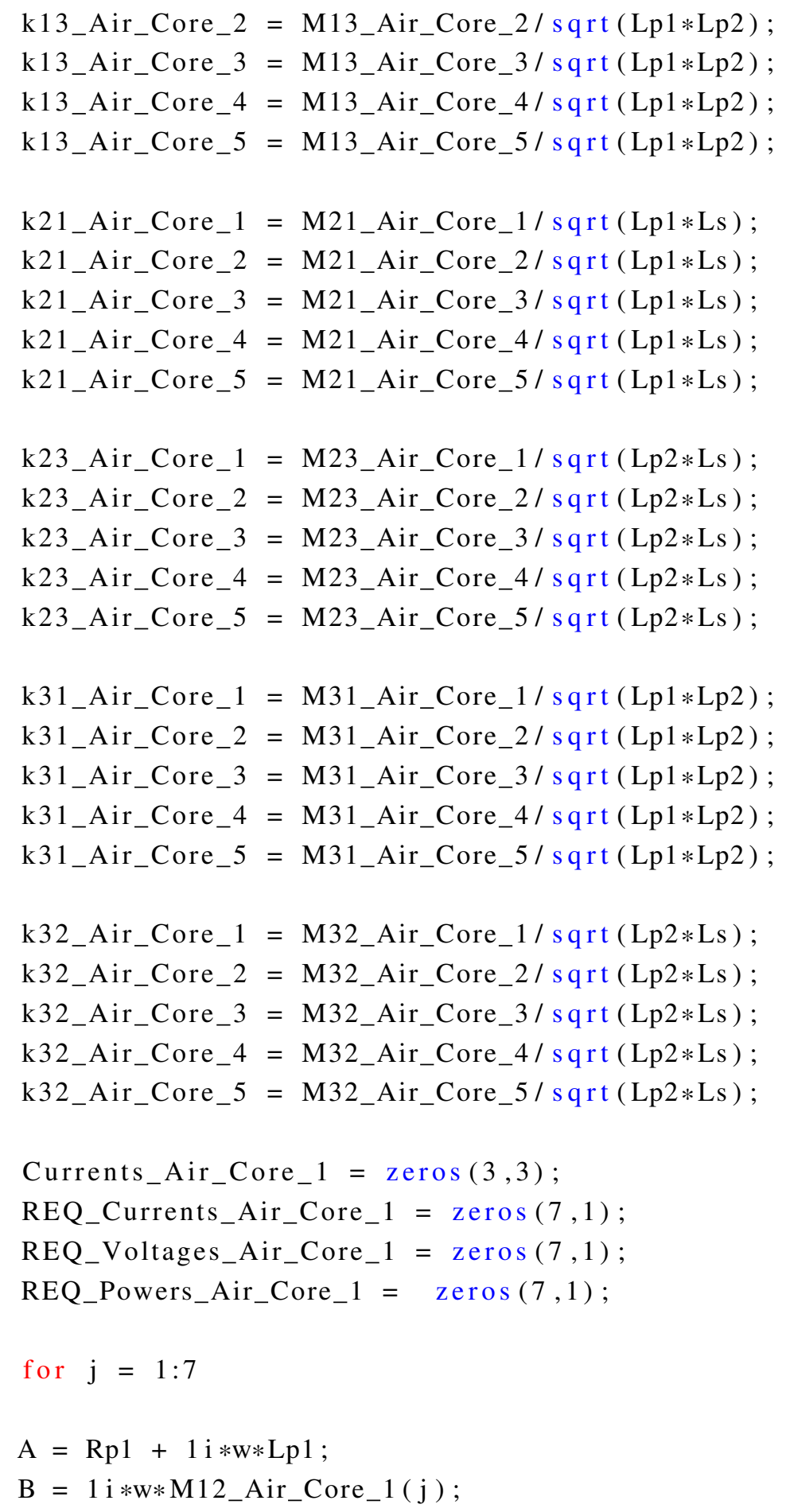




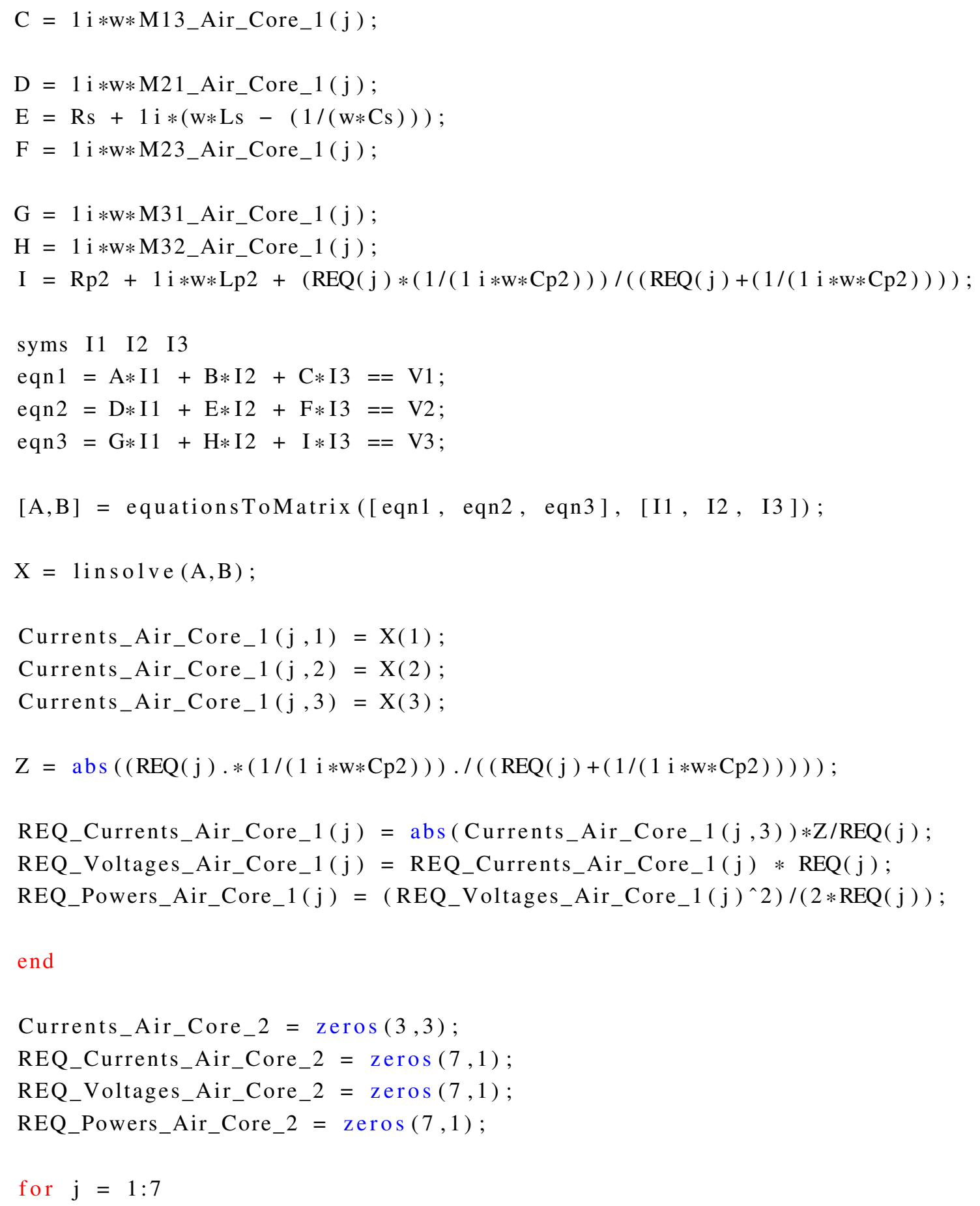




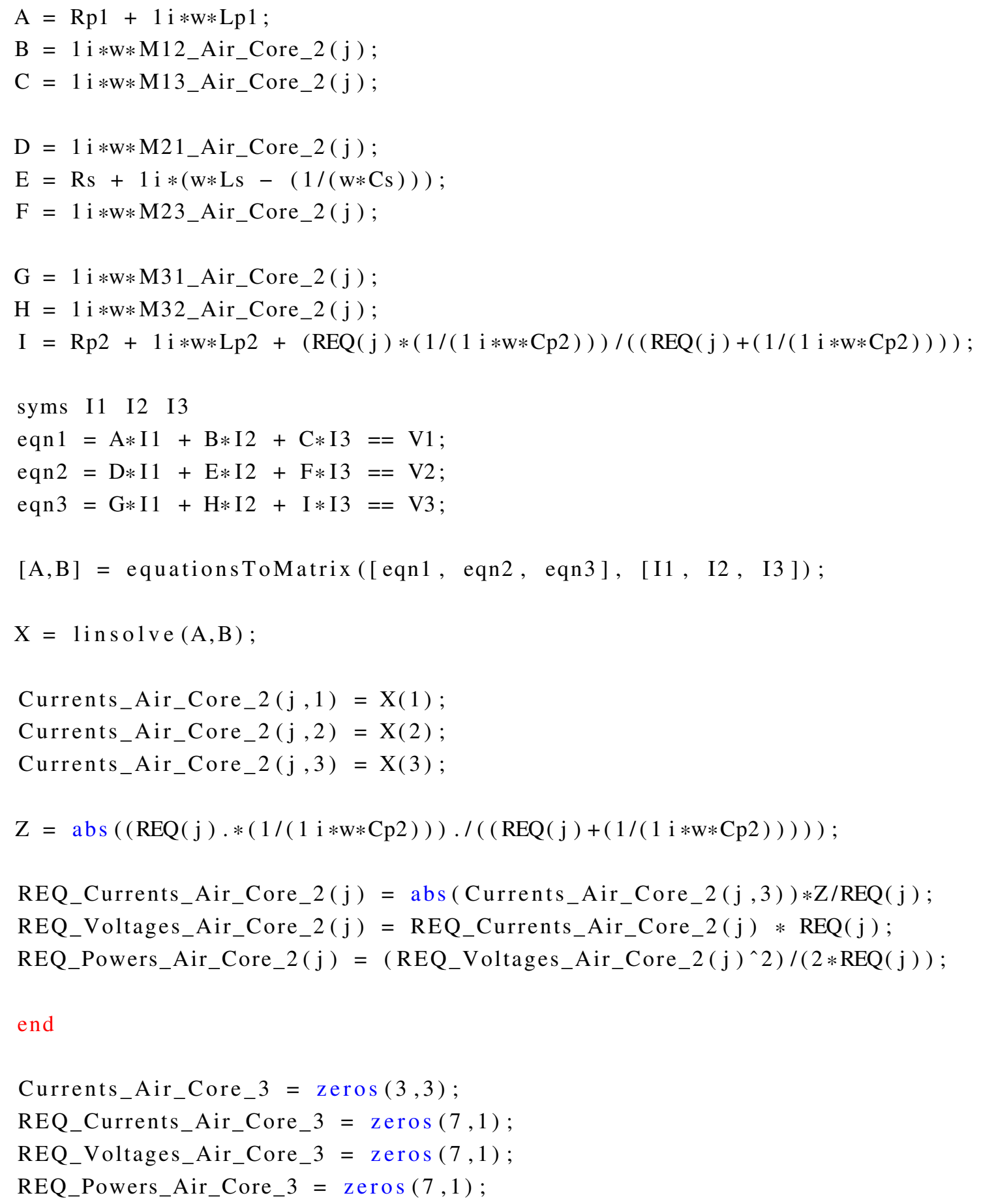




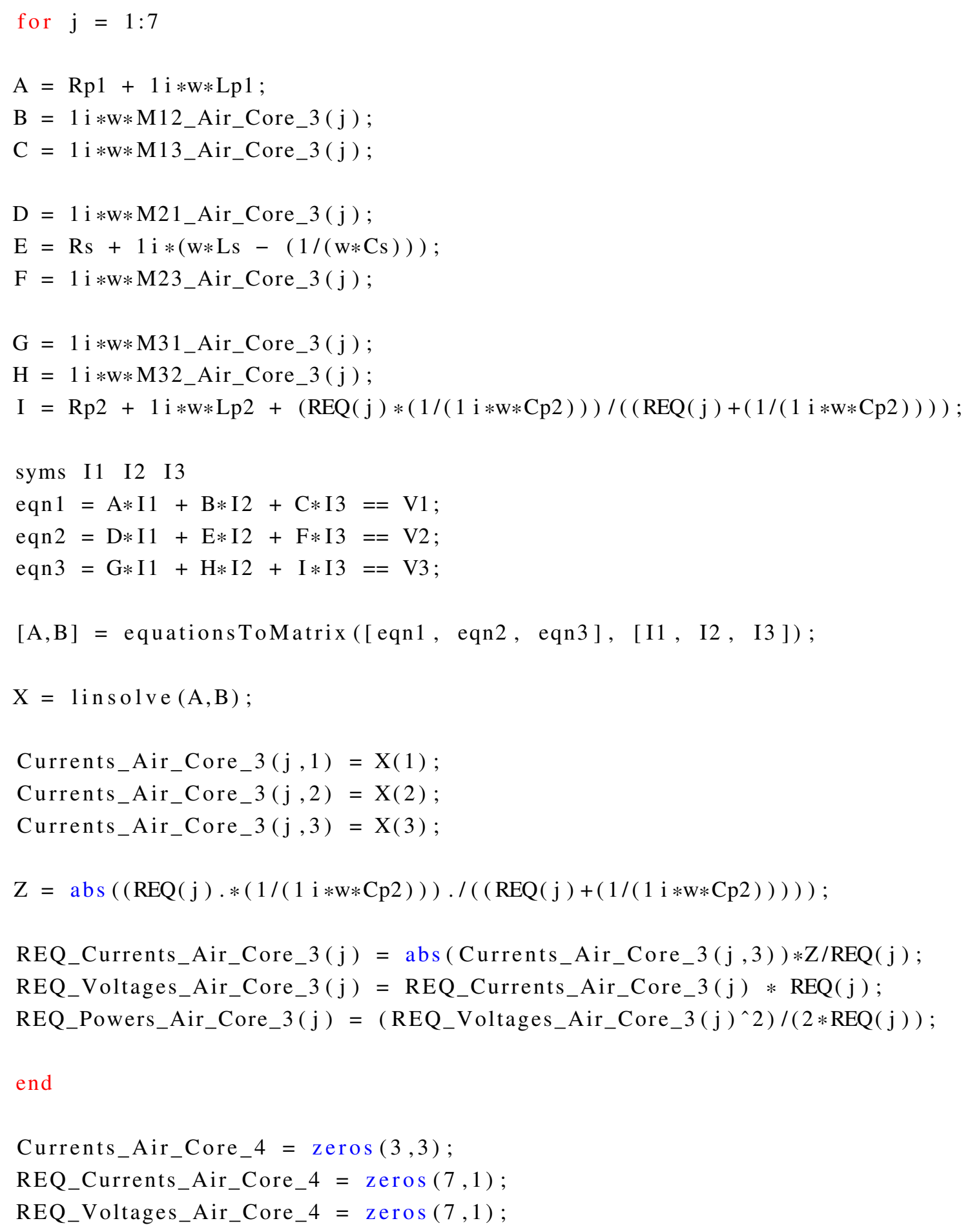




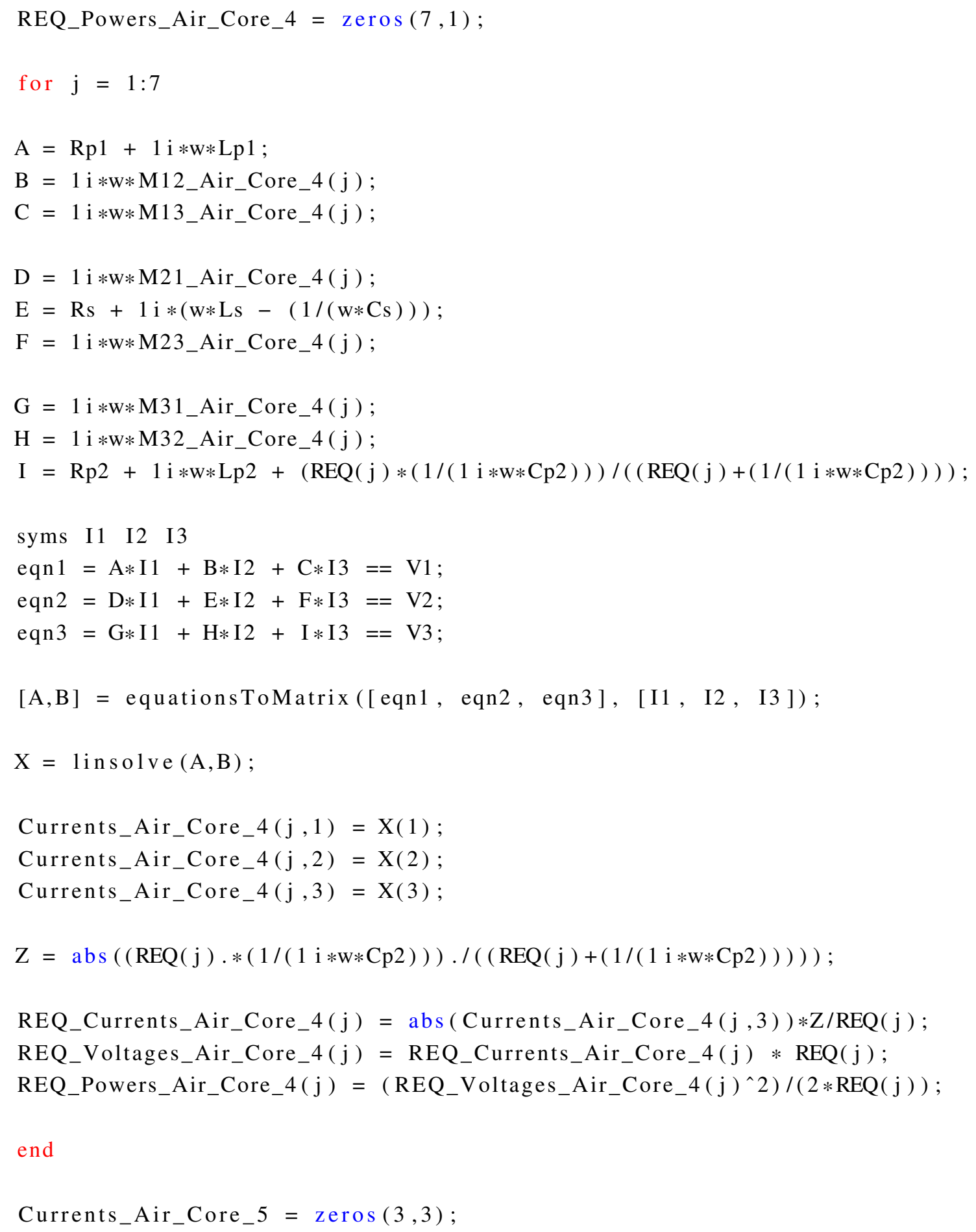




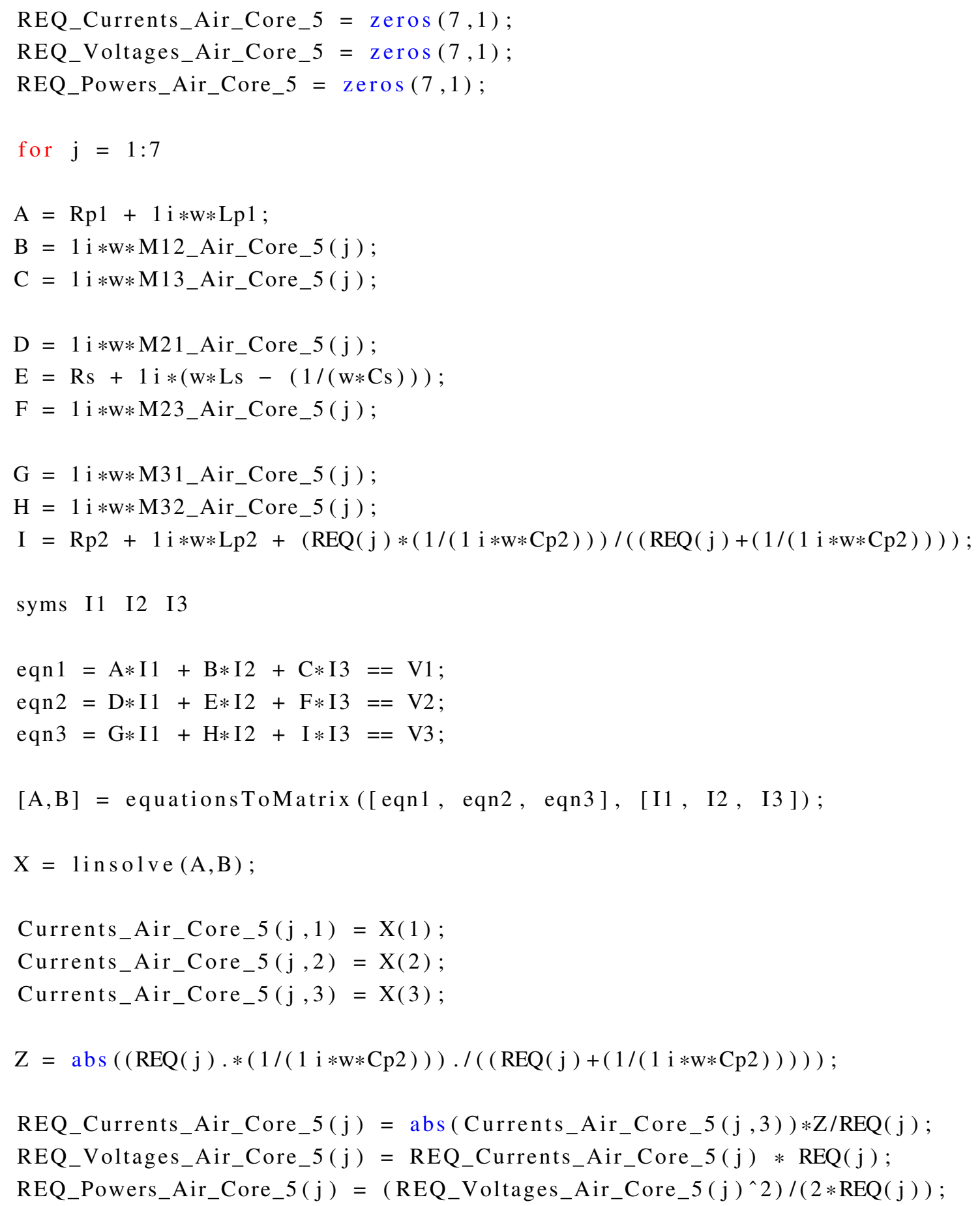




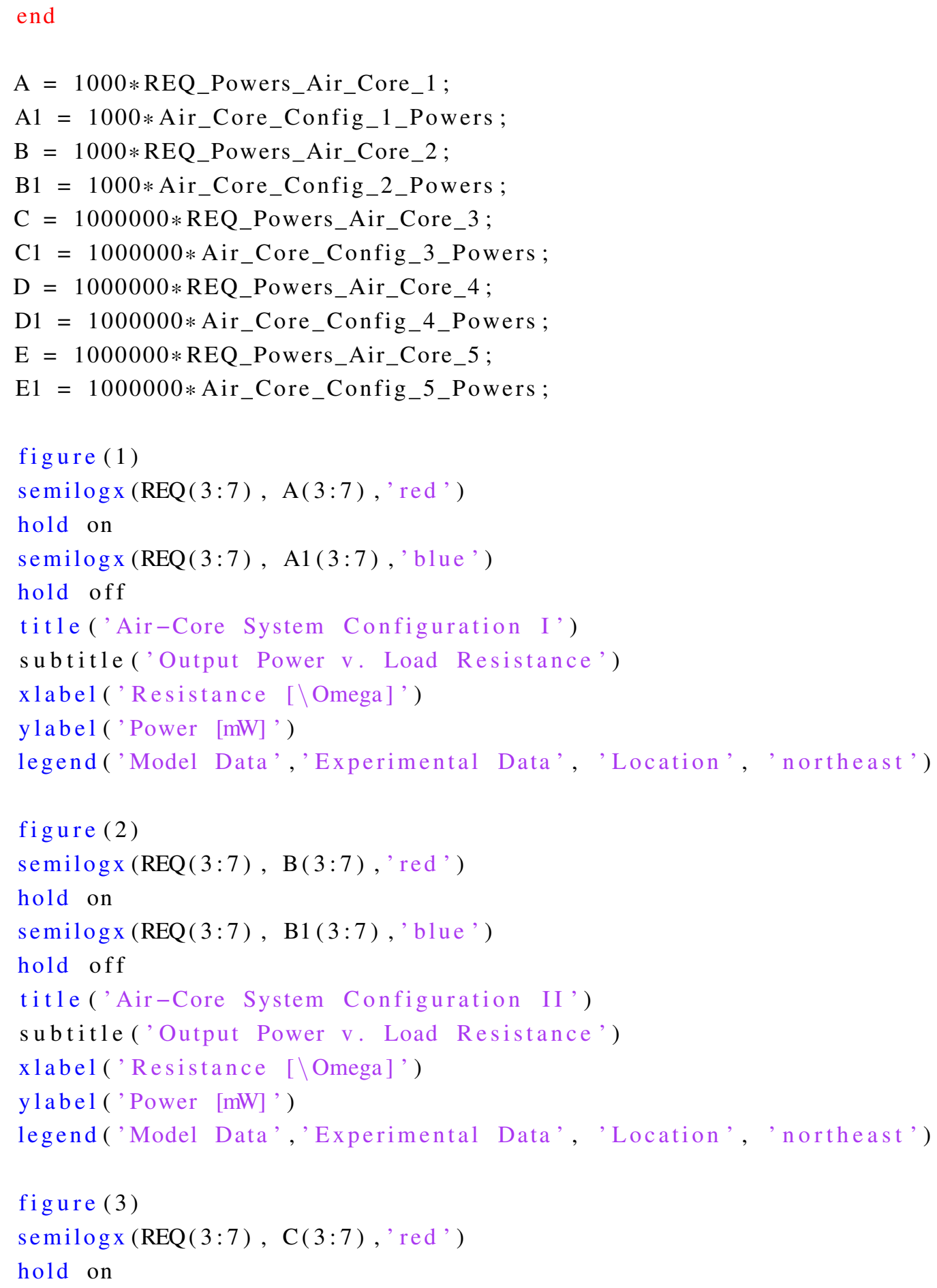




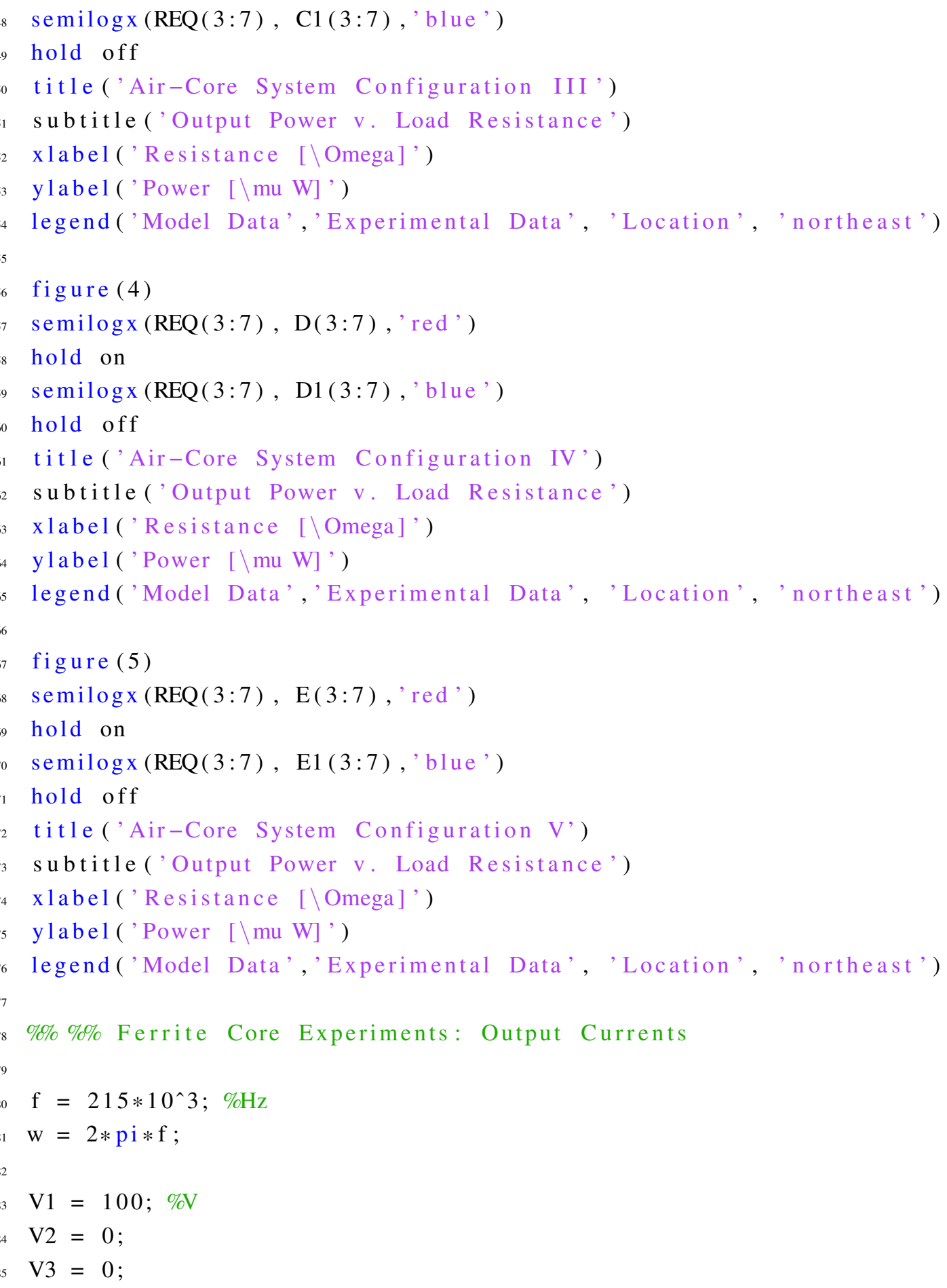




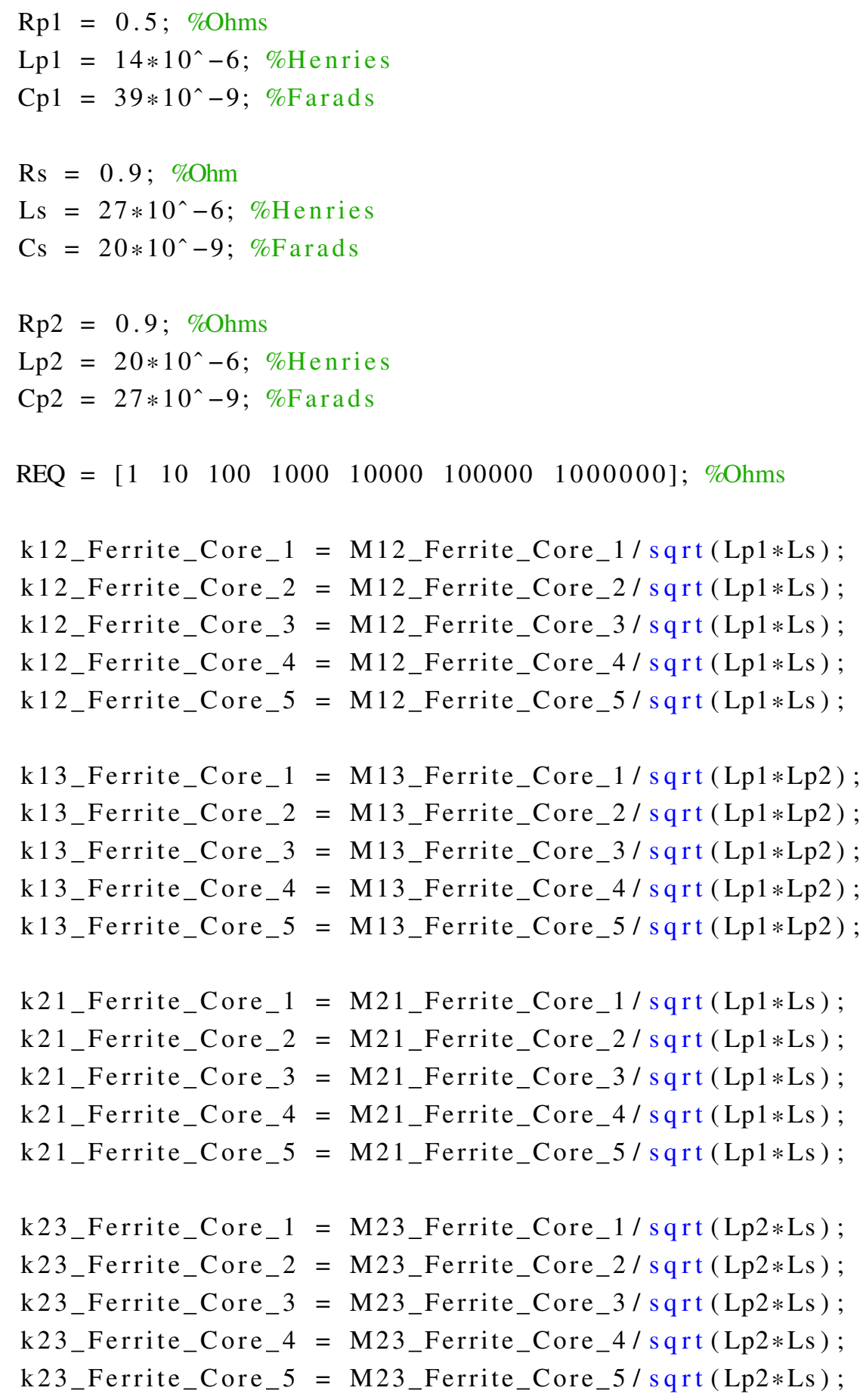




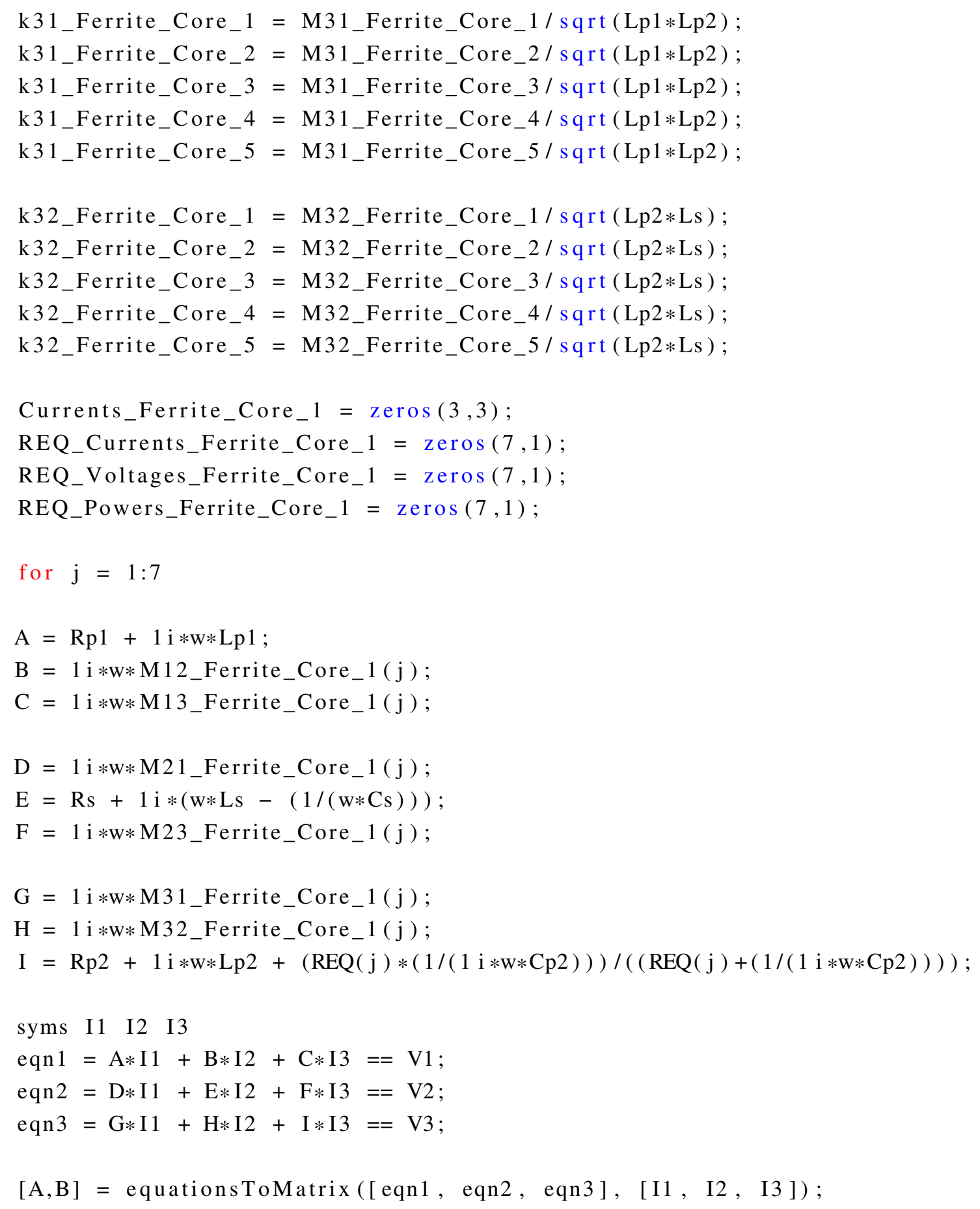




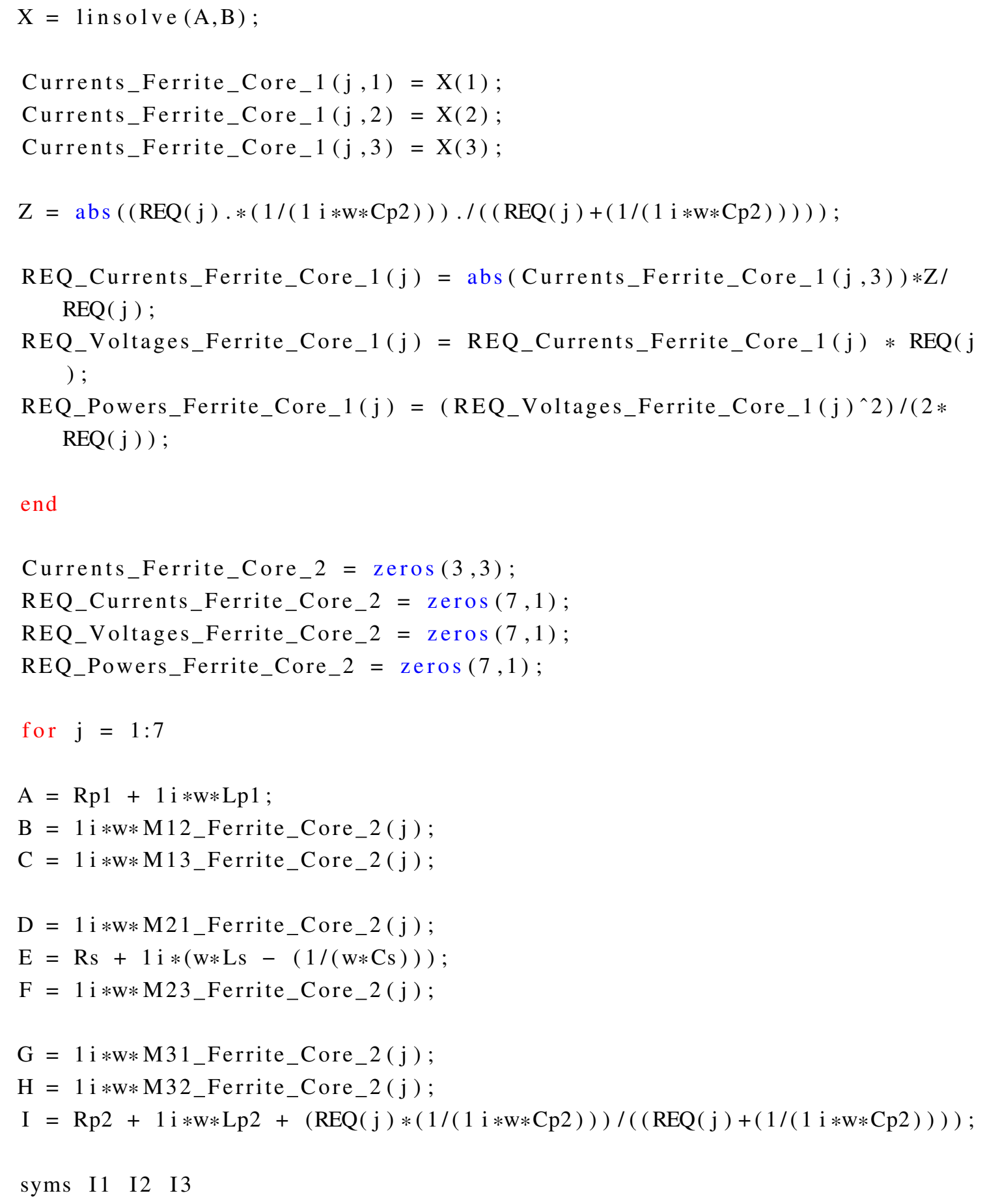




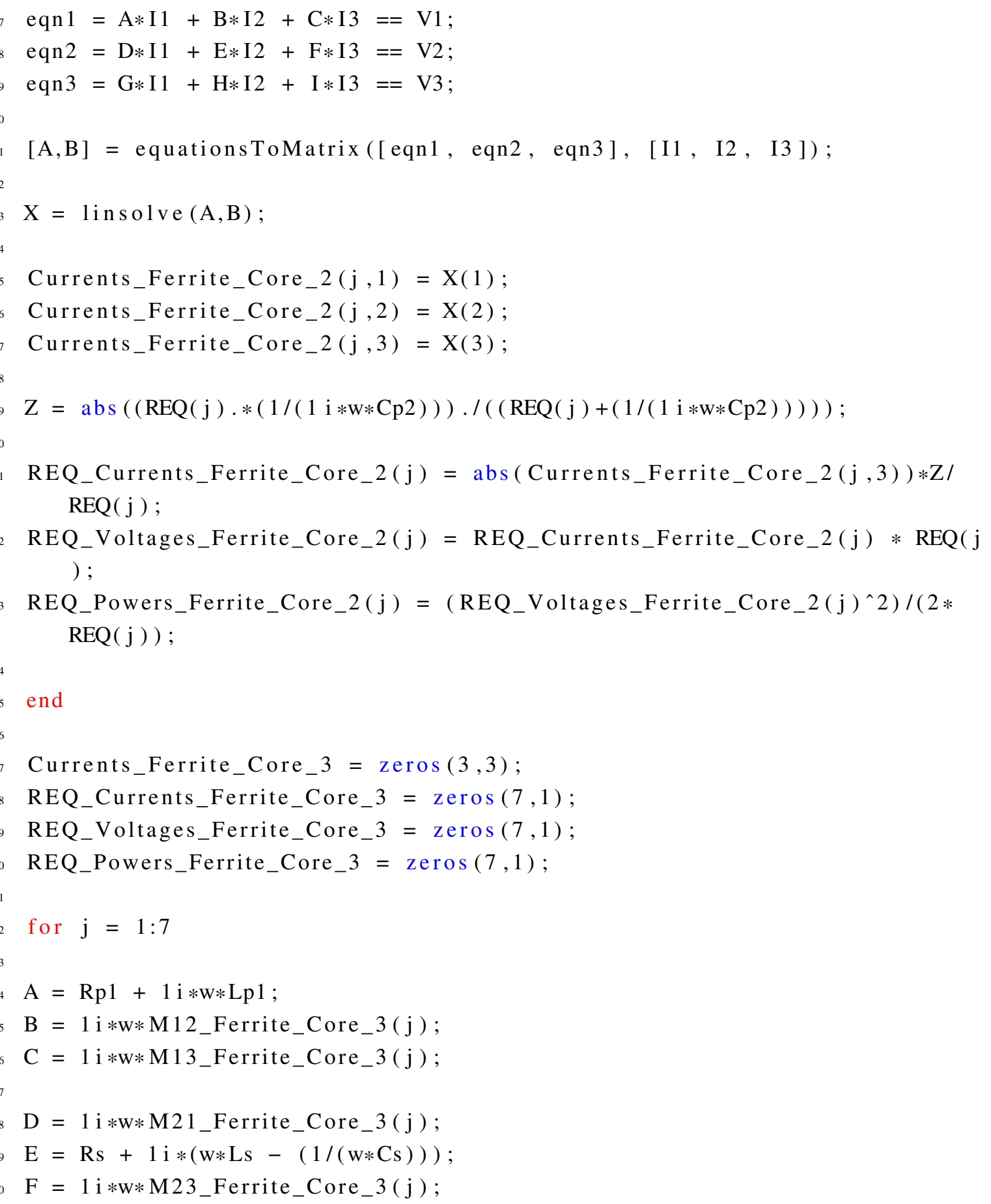




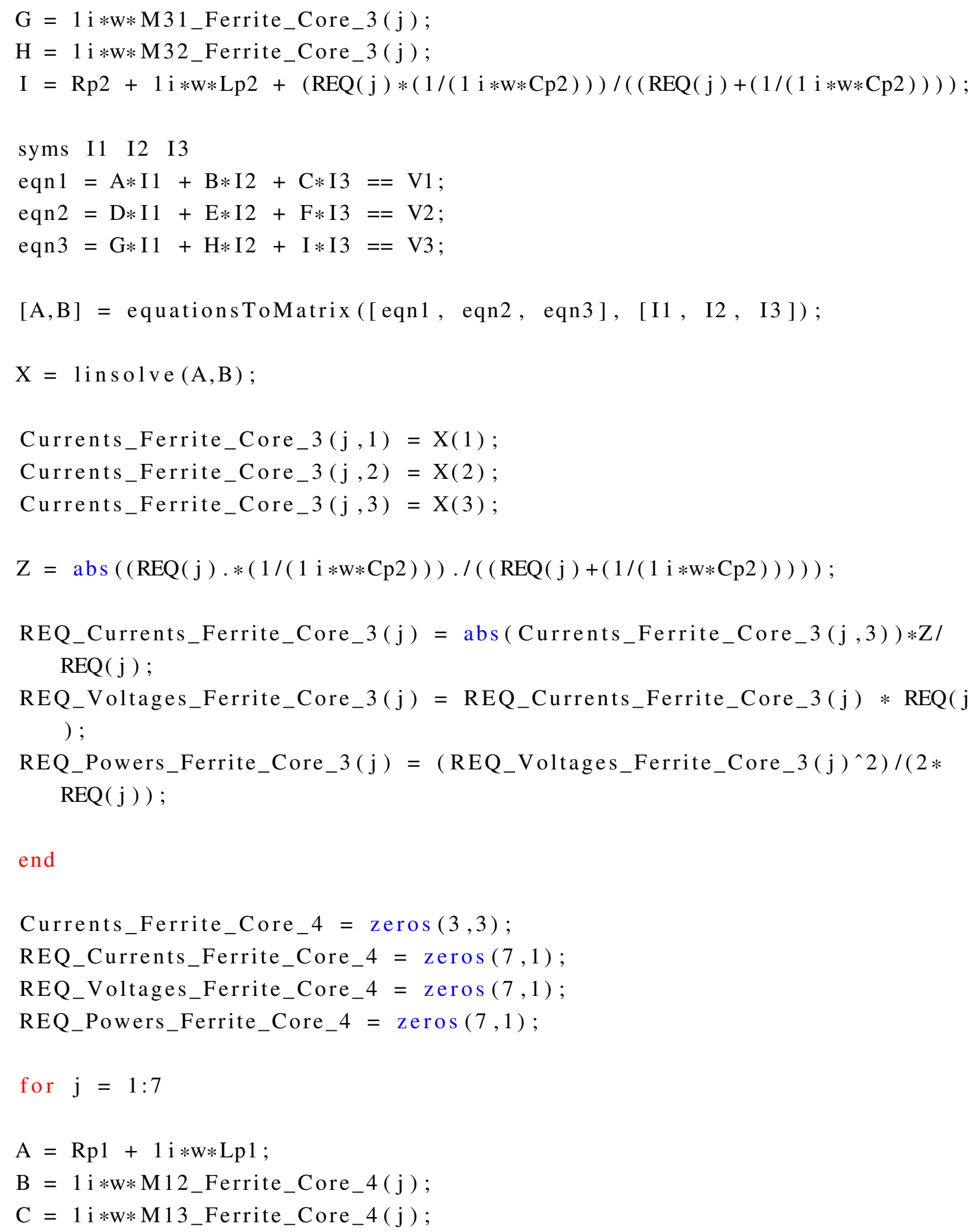




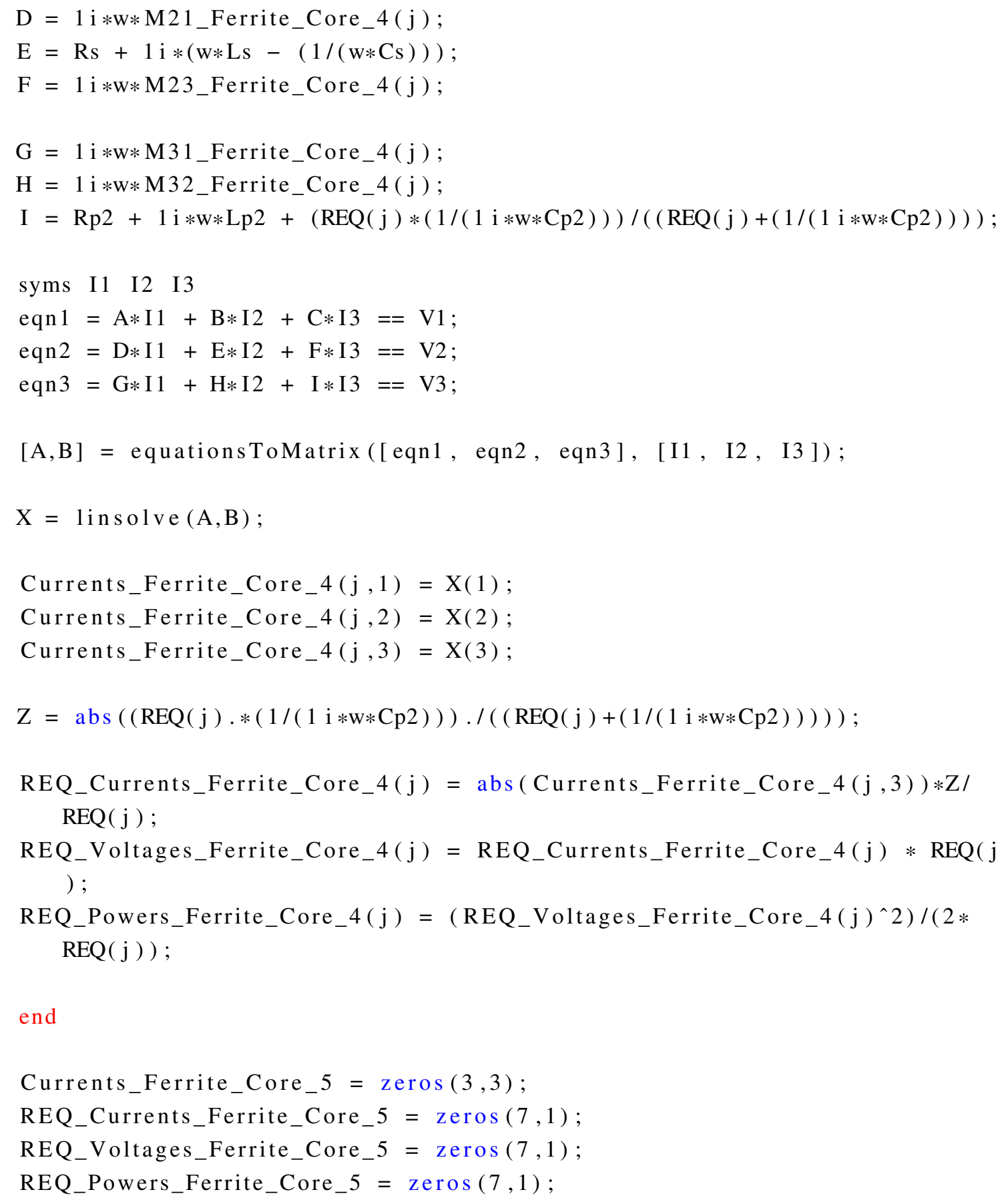




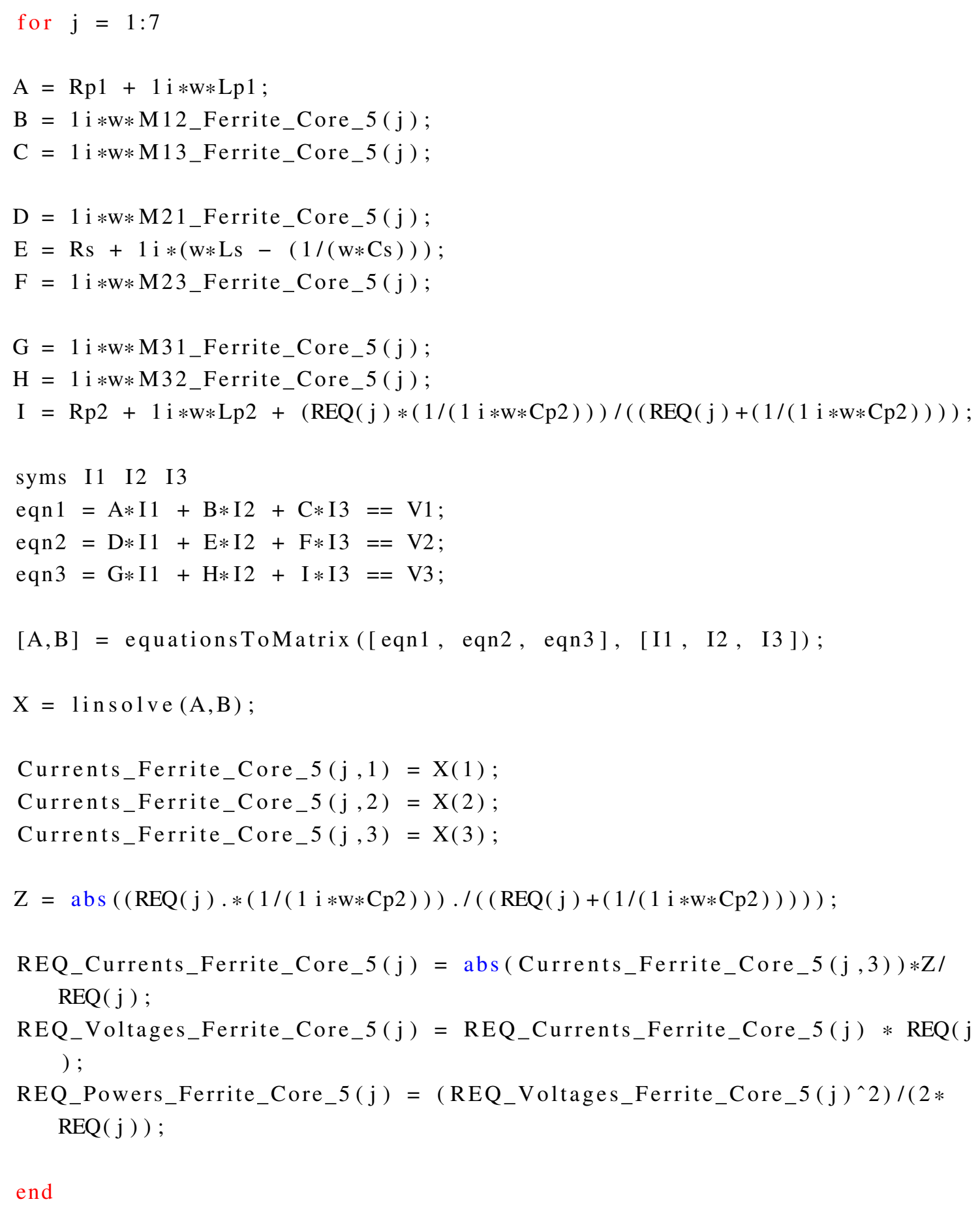




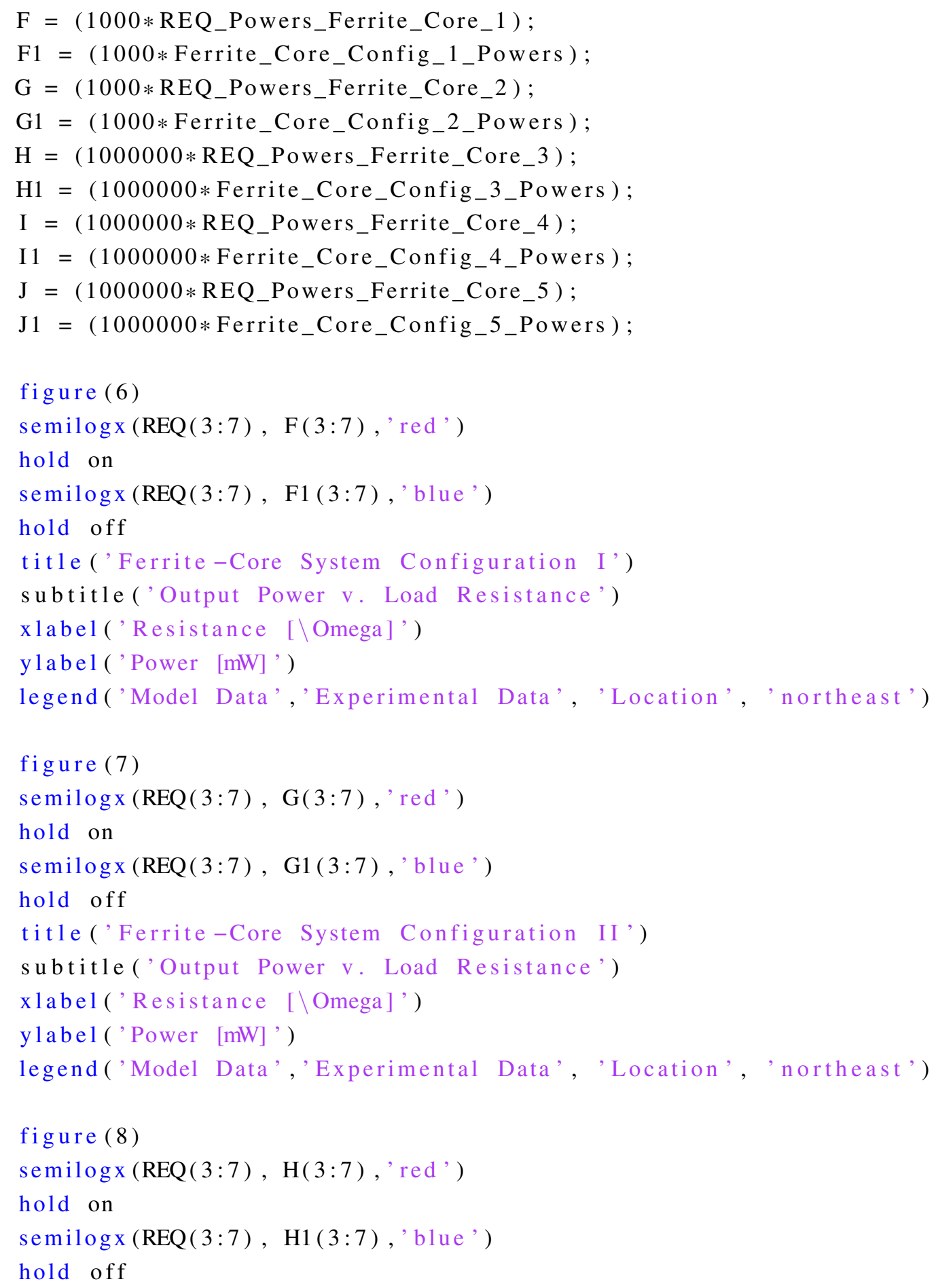




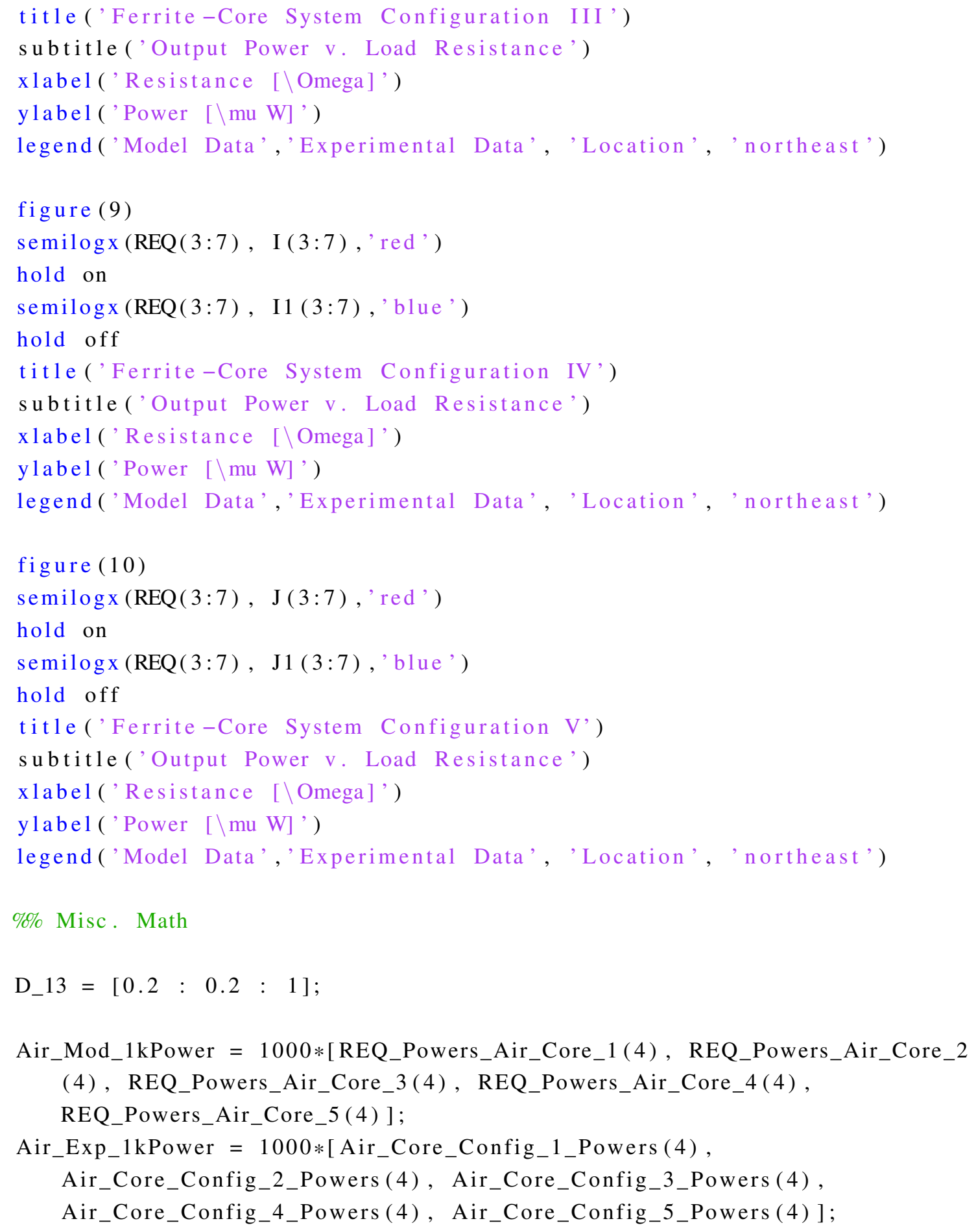


1009

1012

1013

1014

1015

1016

1017

1018

1019

1020

1021

1022

1023

Ferrite_Mod_1kPower $=1000 *\left[\mathrm{REQ} \_\right.$Powers_Ferrite_Core_1 (4), REQ_Powers_Ferrite_Core_2(4)，REQ_Powers_Ferrite_Core_3(4), REQ_Powers_Ferrite_Core_4(4), REQ_Powers_Ferrite_Core_5 (4) ];

Ferrite_Exp_1kPower $=1000 *[$ Ferrite_Core_Config_1_Powers $(4)$, Ferrite_Core_Config_2_Powers(4), Ferrite_Core_Config_3_Powers (4), Ferrite_Core_Config_4_Powers(4), Ferrite_Core_Config_5_Powers(4)];

figure (11)

$\log \log \left(D_{-} 13\right.$, Ferrite_Exp_1kPower, 'blue')

hold on

$\log \log \left(D_{-} 13\right.$, Ferrite_Mod_1kPower, 'cyan')

$\log \log \left(D_{-} 13\right.$, Air_Mod_1kPower, 'magenta')

$\log \log \left(D_{-}\right.$13, Air_Exp_1kPower, 'red')

hold off

title ('Relative Performance at $1 \mathrm{k} \backslash$ Omega')

subtitle ('Output Power v. Distance between TX and RX')

xlabel ('Distance $[\mathrm{m}]$ ')

ylabel ('Power [mW]')

legend('Ferrite Experimental Data', 'Ferrite Model Data', 'Air Model Data ', 'Air Experimental Data', 'Location', 'northeast') 


\section{Acknowledgment}

I would like to thank Dr. David Burnett for his patience, flexibility, and technical expertise throughout the long and arduous completion of this thesis. Additionally, I would like to thank the Honors College faculty, particularly Dr. Yasmeen Hanoosh, Dr. Jesse Hoffman, Mrs. Brianna Avery, and Mrs. Cornelia Coleman for helping me with the various administrative issues I faced. Hopefully, the quality of this work will reflect their efforts in working with me to create the best thesis possible. 


\section{References}

[1] Patrick P. Mercier, and D. Lee, "Introduction to Ultra Low Power Transceiver Design," in ULTRALOW-POWER SHORT-RANGE RADIOS, SPRINGER INTERNATIONAL PUBLISHING, 2016.

[2] SEMTECH, "User Guide - LinkCharge ${ }^{\mathrm{TM}}$ LP Series TSWITX-5V-2RX-EVM Wireless Charging Transmitter (Rev 1.01).” SEMTECH.

[3] Z. Dong, S. Liu, X. Li, Z. Xu, and L. Yang, "A novel long-distance wireless power transfer system with constant current output based on domino-resonator," IEEE Journal of Emerging and Selected Topics in Power Electronics, vol. 9, no. 2, pp. 2343-2355, 2021.

[4] D. C. Burnett, H. M. Fahad, L. Lee, F. Maksimovic, B. Wheeler, O. Khan, A. Javey, and K. S. Pister, "Two-Chip Wireless H2S Gas Sensor System Requiring Zero Additional Electronic Components," 2019 20th International Conference on Solid-State Sensors, Actuators and Microsystems and Eurosensors XXXIII (TRANSDUCERS and EUROSENSORS XXXIII), 2019.

[5] F. Wen, X. Chu, Q. Li, R. Li, L. Liu, and F. Jing, "Optimization on Three-Coil Long-Range and Dimension-Asymmetric Wireless Power Transfer System," IEEE Transactions on Electromagnetic Compatibility, vol. 62, no. 5, pp. 1859-1868, 2020.

[6] M. Wang, J. Feng, Y. Shi, and M. Shen, "Demagnetization Weakening and Magnetic Field Concentration With Ferrite Core Characterization for Efficient Wireless Power Transfer," IEEE Transactions on Industrial Electronics, pp. 1842-1851, 2018.

[7] "Taidacent High Power 24V 200mm One-to-Many Long Distance Wireless Charging Pad Contactless Power Supply Module Can be Used for Multiple Receivers," Amazon, 2010. [Online]. Available: https:// www.amazon.com/gp/product/B07QNF6J6Z/ref=ppx_yo_dt_b_asin_title_o00_s00?ie=UTF8\&amp;psc=1] [Accessed: 12-Aug-2021].

[8] X. Zhai, H. Wang, J. Li, Z. Huang, and R. Gao, "A lightweight wireless charging method for unmanned aerial vehicles," Journal of Physics: Conference Series, vol. 1754, no. 1, p. 012176, 2021.

[9] S. Raju, R. Wu, M. Chan, and C. P. Yue, "Modeling of mutual coupling Between Planar inductors in wireless power applications," IEEE Transactions on Power Electronics, vol. 29, no. 1, pp. 481-490, 2014. 
[10] J. Gao, G. Yan, Z. Wang, P. Jiang, and D. Liu, "A capsule robot powered by wireless power transmission: Design of its receiving coil," Sensors and Actuators A: Physical, vol. 234, pp. 133-142, 2015.

[11] P. T. Theilmann and P. M. Asbeck, "An analytical model for inductively coupled implantable biomedical devices with ferrite rods," IEEE Transactions on Biomedical Circuits and Systems, vol. 3, no. 1 , pp. 43-52, 2009.

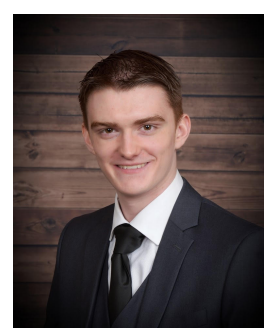

Jakob White is a BS candidate in the Electrical \& Computer Engineering department at Portland State University. During the course of his research and studies, he has been involved in a breadth of electrical engineering work, from designing analog electronics to programming micro-controllers. He hopes to eventually obtain a MS degree and work on cutting-edge analog electronics. 